University of Massachusetts Amherst

ScholarWorks@UMass Amherst

Masters Theses

Dissertations and Theses

December 2014

\title{
Parents' Gender Ideology and Gendered Behavior as Predictors of Children's Gender-Role Attitudes: A Longitudinal Exploration
}

Hillary Paul Halpern

University of Massachusetts Amherst

Follow this and additional works at: https://scholarworks.umass.edu/masters_theses_2

Part of the Community-Based Learning Commons, Community Health and Preventive Medicine Commons, Educational Sociology Commons, Education Policy Commons, Family, Life Course, and Society Commons, Gender and Sexuality Commons, Maternal, Child Health and Neonatal Nursing Commons, Occupational Health and Industrial Hygiene Commons, Psychiatry and Psychology Commons, Social and Cultural Anthropology Commons, Social Work Commons, and the Women's Health Commons

\section{Recommended Citation}

Halpern, Hillary Paul, "Parents' Gender Ideology and Gendered Behavior as Predictors of Children's Gender-Role Attitudes: A Longitudinal Exploration" (2014). Masters Theses. 134.

https://doi.org/10.7275/6487725 https://scholarworks.umass.edu/masters_theses_2/134

This Open Access Thesis is brought to you for free and open access by the Dissertations and Theses at ScholarWorks@UMass Amherst. It has been accepted for inclusion in Masters Theses by an authorized administrator of ScholarWorks@UMass Amherst. For more information, please contact scholarworks@library.umass.edu. 
Parents' Gender Ideology and Gendered Behavior as Predictors of Children's Gender-Role Attitudes: A Longitudinal Exploration

\author{
A Thesis Presented \\ By \\ HILLARY PAUL HALPERN
}

Submitted to the Graduate School of the University of Massachusetts Amherst in partial fulfillment of the requirements for the degree of

MASTER OF SCIENCE

May 2014

Clinical Psychology 
(C) Copyright by Hillary Paul Halpern 2014

All Rights Reserved 
Parents' Gender Ideology and Gendered Behavior as Predictors of Children's Gender-Role Attitudes: A Longitudinal Exploration

A Thesis Presented

by

HILLARY PAUL HALPERN

Approved as to style and content by:

Maureen Perry-Jenkins, Chair

Elizabeth Harvey, Member

Jennifer McDermott, Member

Melinda A. Novak, Department Head

Department of Psychology 


\section{DEDICATION}

To my parents, who have given me the unconditional love and acceptance I needed to be the girl I was and the woman I am today. 


\section{ACKNOWLEDGMENTS}

Many thanks to my advisor, Maureen Perry-Jenkins, for her patient and supportive guidance through the joys and struggles of work and of life. Thanks also to my committee members, Lisa Harvey and Jen McDermott, for their time, encouragement and thoughtful input throughout the many stages of this process. I am most grateful to Aline Sayer and David Arnold for their mentorship and statistical prowess. Many thanks are also due to my lab mates and mentors Aya Ghunney and Katie Newkirk.

My deepest appreciation goes to Karin Garber and Jeff Winer for their friendship and encouragement. Finally, to my husband Noah Halpern - the man who continues to support me tirelessly every step of the way — thank you for all that you do to make my work possible and my life beautiful. 


\begin{abstract}
PARENTS' GENDER IDEOLOGY AND GENDERED BEHAVIOR AS PREDICTORS

OF CHILDREN'S GENDER-ROLE ATTITUDES: A LONGITUDINAL EXPLORATION
\end{abstract}

MAY 2014

HILLARY PAUL HALPERN, B.A., CLARK UNIVERSITY

M.S., UNIVERSITY OF MASSACHUSETTS AMHERST

Directed by: Professor Maureen Perry-Jenkins

This longitudinal study examined the association between parents' early and concurrent gender ideology and gendered behaviors and their children’s gender-role attitudes at age six. Specifically, parents' global beliefs about women's and men's "rightful" roles in society, as well as their work preferences for mothers, were considered in relation to the gender-role attitudes held by their first-graders. In addition, parents’ gendered behaviors, including their division of household and childcare tasks, division of paid work hours, and job traditionality were examined as predictors of children’s gender-role attitudes. Based on previous research, it was hypothesized parents’ early and concurrent behavior and ideology would predict children's gender-role attitudes in unique ways, and that overall, parents' behavior would be more influential than their ideology in the development of their children's understanding of gender roles. It was also hypothesized that fathers' ideologies would be more closely related to sons' attitudes than daughters' attitueds. Partial support was found for these hypotheses, and findings varied across three measures of children's gender-role attitudes. The present study is the first of its kind to examine the relationships between both mothers' and fathers’ gender ideology and 
gendered behavior with children's gender-role attitudes from a longitudinal perspective. Findings from the current study will fill gaps in the literature on children's gender development in the context of the family, and offer the benefit of a longitudinal exploration of the relationship between parents' gender ideologies, gendered behavior, and children's gender-role attitudes. Several limitations, including those related to the nature of the sample, are addressed. 


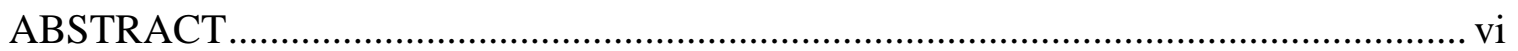

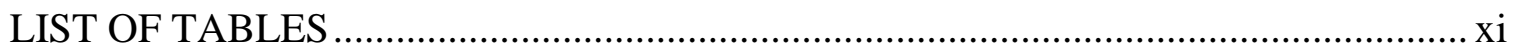

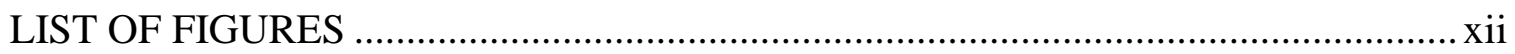

\section{CHAPTER}

I. CHILDREN'S GENDER DEVELOPMENT IN THE FAMILY CONTEXT................. 1

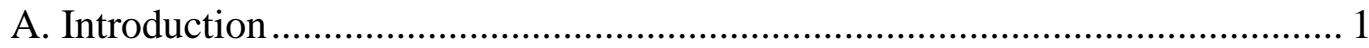

B. Children's Development of Gender-Role Attitudes............................................ 5

1. Gender Development From A Social Cognitive Perspective ................... 5

2. Gendered Preferences and Stereotyping in Early Childhood ................... 6

C. The Relationship Between Parents' Gender Ideology and Children's Gender-

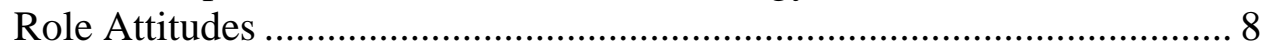

1. The Intergenerational Transmission of Gender Ideology ........................ 9

D. The Relationship Between Parents' Gendered Behavior and Children's Gender-

Role Attitudes ..................................................................................... 10

1. Parents' Division of Household Labor ................................................... 10

2. Parents' Division of Childcare ............................................................ 12

3. Parents' Division of Paid Labor ............................................................ 13

4. Traditionality of Parents' Occupations.................................................... 15

E. The Relationship Between Parents' Gender Ideology, Parents' Gendered Behavior, and Children's Gender-Role Attitudes ..................................... 16

F. The Role of Parent and Child Sex in Children's Development of Gender-Role

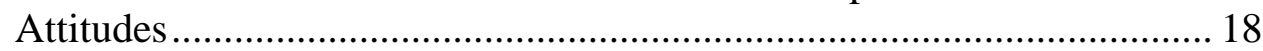

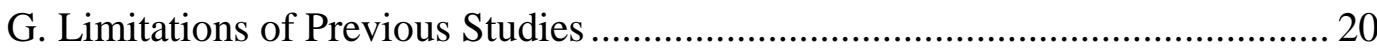

H. Research Questions .................................................................................... 22

II. METHODOLOGY OF THE PRESENT STUDY …………………........................ 26

A. Participants and Procedure......................................................................... 26

B. Measures and Variables ………………………........................................... 27 
1. Parents' Gender Ideology .................................................................. 28

2. Parents' Gendered Behavior.................................................................. 29

a. Division of Household Labor....................................................... 29

b. Division of Childcare Tasks........................................................ 30

c. Parents' Paid Labor...................................................................... 30

d. Traditionality of Parents' Occupations......................................... 31

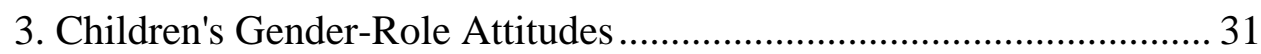

C. Human Subjects........................................................................................ 32

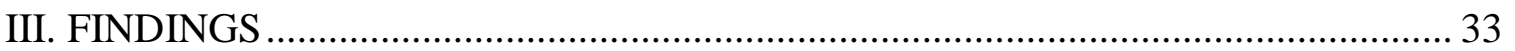

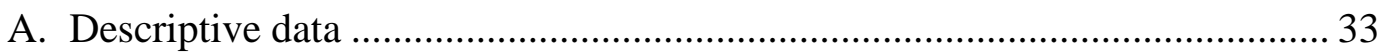

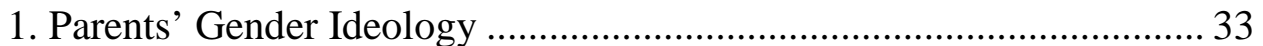

2. Parents' Gendered Behavior ..................................................................... 33

3. Relationships Among Predictor Variables............................................ 34

4. Children’s Gender-Role Attitudes ..................................................... 37

B. Parents' Gender Ideology and Children's Gender-Role Attitudes ..................... 37

C. Parents' Gendered Behavior and Children's Gender-Role Attitudes................. 39

D. Relative Effects of Parents' Gender Ideology and Gendered Behavior on

Children's Gender-Role Attitudes .......................................................... 40

E. Exploratory Analyses ……………………………....................................... 42

1. Sex Role Discrimination (Own Sex)..................................................... 42

2. Sex Role Discrimination (Opposite Sex) ................................................ 43

3. Sex Role Preferences (Adult Figures)..................................................... 43

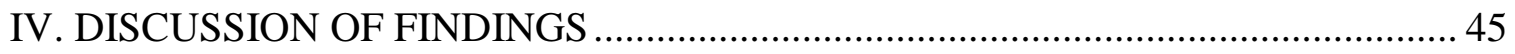

A. Sex Role Discrimination (Own Sex)............................................................. 45

B. Sex Role Discrimination (Opposite Sex) ……………..................................... 48

C. Sex Role Preferences (Adult Figures) ............................................................... 50

\section{APPENDICES}

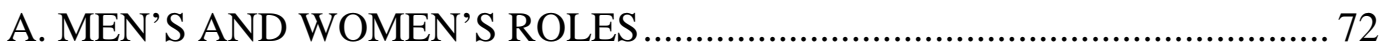

B. ATTITUDES TOWARDS WOMEN SCALE ……………….......................... 75

C. QUESTIONS ABOUT WIVES' AND HUSBANDS' WORK

PREFERENCES AND EMPLOYMENT............................................... 77

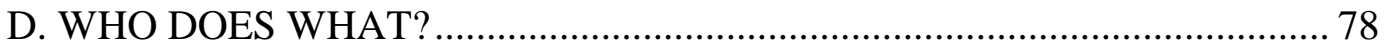

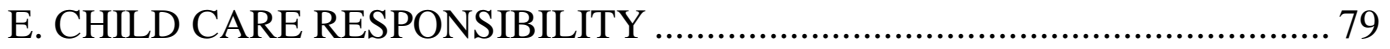

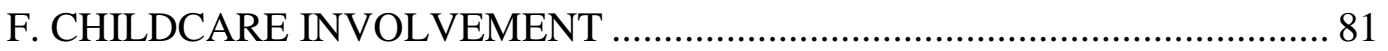




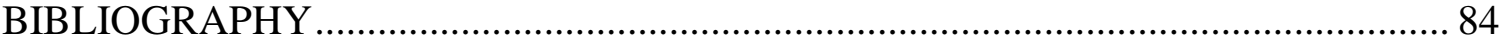


Table

1. Descriptive statistics for mothers' and fathers' early and concurrent predictors of children's gender-role attitudes........................................... 55

2. Intercorrelations between mothers' and fathers' early predictors of children's genderrole attitudes.

3. Intercorrelations between mothers' and fathers' concurrent predictors of children's gender-role attitudes

4. Intercorrelations between principal component variables representing mothers' and fathers' early and concurrent gender ideology and gendered behavior...

5. Children's gender-role attitudes

6. Correlations between principal component variables representing mothers' and fathers' early and concurrent gender ideology and gendered behavior and children's gender-

role attitudes

7. Summary of hierarchical regressions predicting parents' early and concurrent gender ideology and children's gender-role attitudes....

8. Summary of hierarchical regressions predicting parents' early and concurrent gendered behaviors and children's gender-role attitudes.

9. Summary of hierarchical regressions predicting parents' early and concurrent gender ideology and gendered behaviors and children's gender-role attitudes.

10. Summary of hierarchical regressions predicting mothers' early and concurrent gender ideology and gendered behaviors and children's gender-role attitudes.

11. Summary of trimmed exploratory hierarchical regressions predicting children's sex role discrimination (own sex).

12. Summary of trimmed exploratory hierarchical regressions predicting children's sex role discrimination (opposite sex).

13. Summary of exploratory hierarchical regressions predicting children's sex role preferences (adult figures). 


\section{LIST OF FIGURES}

Figure

Page

1. Interaction between mothers' gendered behavior during year six and child sex as it predicts sex role discrimination (own sex) ...................................68

2. Interaction between mothers' gendered behavior during year one and child sex as it predicts sex role discrimination (own sex) in an exploratory model using hierarchical

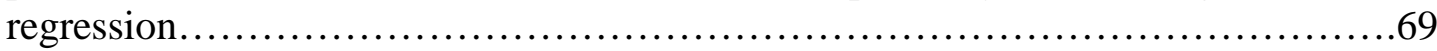

3. Interaction between mothers' gendered behavior during year six and child sex as it predicts sex role discrimination (own sex) in an exploratory model using hierarchical regression........................................................... 70

4. Interaction between fathers' ideology during year one and child sex as it predicts sex role discrimination (opposite sex) in an exploratory model using hierarchical regression................................................................ 


\section{CHAPTER I}

\section{CHILDREN'S GENDER DEVELOPMENT IN THE FAMILY CONTEXT}

\section{$\underline{\text { A. Introduction }}$}

At an early age, children tend to demonstrate stereotyped beliefs about the gender roles that are dominant within their culture (Berk, 2009). Researchers have documented young children's tendency to "essentialize gender"—-that is, to make assumptions about males and females based on their sex alone (Gelman, Taylor \& Nguyen, 2004). Rigid adherence to stereotypical gender roles can have negative consequences in childhood and beyond, as these stereotypes can limit children's educational and occupational aspirations (Liben, Bigler, \& Krogh, 2002). Thus, it is important to examine the factors that contribute to children's practices of gender stereotyping.

A growing body of literature examines the intergenerational transmission of gender ideology, or the system of values, beliefs and attitudes a person holds about the meaning of biological sex and gender and how this transmission occurs within families (Kroska, 2000). While the term "sex" refers to biological characteristics held by an individual (e.g., genital and hormonal features), "gender" represents sociocultural expectations about the meaning of being male or female, as well as the experience of being male or female as it is constructed and enacted through experiences within a social context (Fausto-Sterling, Coll, \& Lamarre, 2012; Wickstrom, 2010). In this paper, "sex" is used to distinguish between biological characteristics of boys and girls or men and women, while "gender" is used in reference to beliefs and expectations related to the meaning of being male or female.

Social cognitive theory emphasizes the roles of both individual development and children's social environments in their construction of beliefs about the roles of men and women 
(Bussey and Bandura, 1999; Martin \& Ruble, 2009). Although there are many factors involved in the creation of a child's social environment, parents' roles are among the most influential in terms of how children learn about gender (Cunningham, 2001b). Research points to a relationship between parents' gender ideologies—-meaning their attitudes and beliefs about gender—and children and adolescents' gender-role attitudes (Epstein \& Ward, 2011; Fulcher, 2010; Sutfin et al., 2008), such that traditionally-minded parents are likely to have children with more rigid ideas about gender, while parents with more egalitarian beliefs about gender roles tend to have children who are more flexible in their thinking about this topic.

In addition to parents' ideology, it is also likely that parents' gendered behaviors—that is, the extent to which a parent performs activities that either enforce or defy gender stereotypesplay a role in shaping their children's gender-role attitudes (Barak, Feldman, \& Noy, 1991). Many studies have considered how parents' division of gendered labor, including housework, childcare and paid labor, is related to children's beliefs about gender. For example, parents' division of paid and unpaid labor along traditional gender roles has been linked to children's development of traditionally gendered career aspirations (Fulcher, Sutfin \& Patterson, 2007). Parents' division of labor has also been found to predict the gendered behavior of their offspring well into adulthood. Cunningham (2001a; 2001b) found that parents' more equal division of household labor was linked to adult sons' performance of more housework, and the more time mothers spent in paid employment, the less housework adult daughters performed relative to their partners.

Previous research suggests that children learn about gender through both ideological and behavioral messages, highlighting parents' engagement in both direct and indirect forms of communication with their children around gender roles and expectations (Cunningham, 2001a; 
Cunningham, 2001b). Despite substantial evidence that both parents' ideologies and performance of gendered labor predict children's gender-role attitudes, it is unclear whether children attend more to ideological or behavioral messages as they develop beliefs about gender roles and the relationship between sex and gender. The current study examines both parental ideology and parental behavior as independent predictors of children's gender-role attitudes. In addition, I test the hypothesis that parents' gendered behaviors are better predictors of children's gender-role attitudes than parents' gender ideology.

Another important question concerns how children in two-parent households receive messages about gender from their mothers and fathers. Literature on parents' gender ideology has focused almost exclusively on mothers' beliefs (Cunningham, 2001a; Fulcher, 2010); less is known about how fathers' beliefs play a role in predicting how children think about gender. In addition, although a considerable body of research has considered the division of household and paid labor among married heterosexual couples (Deutsch \& Saxon, 1998; Erickson, 2005; Patterson, 2004; South \& Spitze, 1994), little is known about how the many components of parents' gendered labor (i.e., the combined effects of parents' household, childcare, and paid labor division) might impact children's gender-role attitudes (Cunningham, 2001a; Fan \& Marini, 2000). Finally, although there is evidence that both mothers' ideology and behavior are related to their children's gender-role attitudes (Cunningham, 2001; Fan \& Marini, 2000; Fulcher, 2010), because of fathers' under-representation in this area of research, it is unclear whether children in two-parent heterosexual families attend more to one parent's ideology and behavior as opposed to the other parent's. Thus, the present study also seeks to determine whether mother's ideology and behavior are better predictors of children's gender-role attitudes than those of their husbands. 
Finally, although research suggests that the sex of both the parent and child play a role in how ideas about gender are passed across generations, there is conflicting evidence regarding the nature of this relationship. Some authors suggest that mothers and fathers treat boys and girls differently (Sutfin, Fulcher \& Patterson, 2008), while other authors posit that the types of interactions children have with mothers and fathers are inherently different, regardless of children's sex (McHale, Crouter \& Whiteman, 2003). For example, mothers tend to perform more repetitive daily childcare tasks, such as feeding and dressing their child, while fathers tend to engage with children through play (McHale et al., 2003). A third body of literature suggests that both parent and child sex matter in terms of how parents communicate about gender and the messages that children take away from these interactions (Carlson \& Knoester, 2011). Thus, to date, the research findings are inconclusive regarding the role of parent and child sex in relation to children's gender development processes.

In the following literature review, I examine research on the linkages between parents' gender ideology and gendered behaviors and children's gender-role attitudes. I begin with an overview of social cognitive theory, which will provide a framework for this investigation. Second, I review what is known about the development of gender-role attitudes in early childhood, and examine the ways in which parents' gender ideology has been linked to children's gender stereotyping. Next, I review literature on how parents' gendered behaviors—namely the division of household labor, division of childcare, and division of paid labor-are related to children's gender stereotyping. In addition, I consider how parents' job traditionality—or the extent to which parents' positions in paid employment are more often held by women or menplays a role in predicting how children think about gender. I also examine the limited evidence suggesting that the combination of parents' ideology and behavior can predict children's gender- 
role attitudes. In addition, I review findings on the roles of parent and child sex in the transmission of gender-role attitudes. Finally, I examine methodological concerns and limitations of previous studies.

\section{B. Children's Development of Gender-Role Attitudes}

The development of knowledge about sex differences, gender stereotypes and genderbased prejudice and discrimination is thought to be an ongoing process throughout the stages of childhood (Martin \& Ruble, 2009). The period of time surrounding children's transition to first grade, when children are aged five to seven, is a particularly interesting time to study these types of attitudes, as research suggests that children have developed a working knowledge of gender roles (Durkin \& Nugent, 1998; Martin \& Ruble, 2009; Ruble \& Martin, 1998) and are the most rigid in terms of their beliefs about gender during this period (Etaugh and Liss, 1992; Huston, 1983; Trautner, Ruble, Cyphers, Kirsten, Behrendt, \& Hartmann, 2005).

Researchers have used a variety of theoretical frameworks to explain how children develop knowledge about sex differences and gender roles (Martin \& Ruble, 2009; Ruble, Martin, \& Berenbaum, 2006). The current study draws upon social cognitive theory in considering children's development of gender-role attitudes within the context of the family.

\section{Gender Development From A Social Cognitive Perspective}

A social cognitive theory of gender development holds that humans are active agents in their own learning processes. A central tenet of this theory is the idea that cognitive processes are bidirectional: as a person develops, they interact with others and establish a social network. Within this network, individuals continue to develop at a cognitive level, creating a sort of feedback loop whereby social experiences and cognitive processes inform one another (Bussey 
and Bandura, 1999; Martin \& Ruble, 2009). This framework emphasizes the role of a child's social environment in their construction of beliefs about the roles of men and women.

Social cognitive theory suggests that as children develop the capacity to differentiate between males and females, modeling plays an important role in processing and applying this knowledge. Parents are likely the most influential figures in a child's life when it comes to modeling gender through both implicit and explicit cues. Although this theory suggests that learning by example is a crucial component of one's development, individual differences also play an important role in how skilled a child feels at mastering what is modeled, as well as how they enact modeled behavior and the types of responses their behavior elicits from others (Bussey \& Bandura, 1999). These two components of development—-the individual and the social—constantly interact, increasing the uniqueness of each individual's experiences surrounding the role of gender in their lives (Martin \& Ruble, 2009).

Applying social cognitive theory to the study of how parents' gender ideology and gendered behavior predict children's development of gender-role attitudes highlights the balance between two sets of influential factors: what parents model directly and indirectly, and a child's unique cognitive processes. Because we can expect that five- to seven-year-olds will have already developed an understanding of sex differences and tend to hold rigid beliefs about gender roles (Durkin \& Nugent, 1998; Ruble \& Martin, 1998; Trautner et al., 2005), the transition to first grade is a particularly interesting time to study children's gender-role attitudes at cognitive and social levels.

\section{Gendered Preferences and Stereotyping in Early Childhood}

Many studies have examined the gendered nature of preschoolers' preferences regarding toys and activities (Durkin \& Nugent, 1998; Ruble \& Martin, 1998), suggesting that by the time 
children reach kindergarten, girls tend to demonstrate stereotypically feminine preferences, while boys tend to demonstrate stereotypically masculine interests.

A longitudinal study that followed 82 children from kindergarten to age 10 found that children's beliefs about gender differences are the most rigid when children are between ages five and seven (Trautner et al., 2005). In this study, rigidity appears to be at the opposite end of the attitudinal spectrum from flexibility; when children's attitudes are more rigid, they tend to define traits as either masculine or feminine (but not both). Flexibility, on the other hand, represents the ability to consider a trait to be masculine, feminine, or both. On average, flexibility does not appear to be characteristic of five- to seven-year-olds' understanding of gender.

It has been suggested that after approximately age seven, children continue to acquire knowledge about gender stereotypes, but become more flexible in their application of these beliefs (Etaugh and Liss, 1992; Huston, 1983; Trautner et al., 2005). In other words, despite awareness of stereotypes, older children are increasingly likely to acknowledge similarities between males and females (Trautner et al., 2005). Because studies like Trautner and colleagues' tend to focus on normative development, it is unclear how much children may differ in terms of their rigidity or flexibility as a function of contextual factors, such as parental beliefs and behavior.

Other studies have focused more on the types of traits and behaviors that children tend to identify as masculine or feminine. Giles and Heyman (2005) compared stereotyping beliefs in a group of 40 preschoolers (ages three to five) and a group of 40 seven- and eight-year-olds. Researchers read scenarios to participants in which a character portrayed either an act of relational aggression or an act of physical aggression, and participants were asked whether the character in question was a boy or a girl. Both boys and girls in each age group rated boys as 
more likely to be the perpetrators of physical aggression, and girls as more likely to be the perpetrators of relational aggression. These findings were relatively consistent across age groups, suggesting that older children continue to use gendered stereotypes to understand and interpret situations. While these findings contradict those of Trautner et al. (2005) regarding the change in children's stereotyping tendencies over time, both sets of findings suggest that around the time that children enter first grade, both boys and girls utilize gender stereotypes. Giles and Heyman (2005) and Trautner et al. (2005) employ theoretical frameworks that emphasize children's learning and use of cognitive strategies in the process of creating and using stereotyped knowledge. However, in their study of children's gender development processes, these authors do not consider the role of situational factors (such as parents' division of labor) in children's acquisition of stereotyped beliefs. These findings must be understood in combination with literature that addresses the importance of social context.

\section{The Relationship Between Parents' Gender Ideology and Children's Gender-Role $\underline{\text { Attitudes }}$}

Studies that relate parents' gender ideology to attitudinal outcomes in children and adolescents generally conceptualize ideology on a spectrum. Traditional views—meaning the idea that females should engage in more stereotypically feminine behaviors, and males in more stereotypically masculine behaviors—represent one end of this spectrum, while egalitarian perspectives_-guided by a belief in equality between the sexes—represent the other (Epstein \& Ward, 2011; Fulcher, 2010; Leve \& Fagot, 1997; Sutfin, Fulcher, Bowles, \& Patterson, 2008). Research suggests that there tend to be positive associations between parents' gender ideologies and their children and adolescents' gender-role attitudes (Epstein \& Ward, 2011; Fulcher, 2010; Sutfin et al., 2008). 


\section{The Intergenerational Transmission of Gender Ideology}

Using a modified version of the Sex Roles Learning Index (SERLI; Edelbrock \& Sugawara, 1978) to measure children's gender-role attitudes, Fulcher (2010) found that when mothers held more traditional ideas about children's gender roles, their children (aged 7-12) tended to report gender-stereotyped career aspirations. The author interpreted these findings through a social cognitive lens by considering children's sense of self-efficacy, or the belief that one's own behavior can enable them to achieve desired outcomes (Fulcher, 2010). Fulcher argued that the more children perceive themselves as having the abilities to develop a certain skill set (such as those required for a particular career), the more likely they are to engage in activities that require those skills, and the more they will exert effort and perseverance in developing and honing those skills. Results of this study suggest that mothers' gender ideology predicts children's self-efficacy with regard to children's occupational aspirations. Thus, when mothers expected their children to be interested in traditionally gendered careers, children tended to demonstrate greater efficacy in gender-stereotypical domains. Fulcher argued that this increased efficacy fostered children's increased interest in those careers that promote gender stereotypes.

Although this study considered only the effects of mothers' ideology (with no attention to the influence of fathers), these findings suggest that there is a relationship between parents' beliefs about gender and their children's gendered interests. Furthermore, the gender-role attitudes that children develop are likely to contribute to the types of skills they believe themselves to have, and the types of goals they set.

A similar study showed that both lesbian and heterosexual parents' beliefs about appropriate gendered behavior for their children (ages 4 to 6) were associated with children's 
gender-role attitudes, such that parents who held less traditional ideas about gender roles had children whose attitudes were also less traditional (Sutfin et al., 2008). Heterosexual parents in this study were more likely than lesbian mothers to create gender-stereotyped environments for their children; specifically, children of heterosexual parents tended to have bedrooms that were decorated using traditionally gendered visual themes. Again, these authors argued that social cognition patterns could explain the development and perpetuation of children's gender stereotyped beliefs, as living in an environment that reinforces traditional notions of gender could impact the development of children's interests.

\section{The Relationship Between Parents' Gendered Behavior and Children's Gender-Role}

\section{$\underline{\text { Attitudes }}$}

In addition to demonstrating ideological beliefs about gender, parents engage in behavior that delivers gendered messages to their children. For example, parents may divide paid labor and household labor in a traditional manner; alternatively, parents may engage in gender atypical household tasks (Bronstein, 2006). The following section of this paper considers three different domains in which parents may demonstrate gendered behavior: through their performance of household labor, childcare tasks, and paid labor. In addition, the traditionality of parents' occupations is considered.

\section{Parents' Division of Household Labor}

Heterosexual couples tend to show specialized patterns of household labor, whereby women spend more time on housework across the transitions to marriage and parenthood, while men spend less time engaging in household labor after making these transitions (Perkins \& DeMeis, 1996; South \& Spitze, 1994). For example, in a study of lesbian and heterosexual couples with children aged four to six, Patterson, Sutfin and Fulcher (2004) found that wives 
spent more time in unpaid household and family-related labor, while husbands spent more time in paid employment positions.

Furthermore, among heterosexual couples with children, women tend to perform more household labor than men. For example, in a sample of college-educated adults under 35, mothers reported performing a dramatically higher portion of household labor than women without children, even when mothers held full-time jobs outside the home (Perkins \& DeMeis, 1996). While mothers tended to view household labor as obligatory, fathers tended to view household labor as voluntary, suggesting that parents' ideology and behavior are likely to be interrelated. Other studies support the idea that women and men are likely to act in accordance with their beliefs (Gervai, Turner \& Hinde 1995; Perry-Jenkins \& Crouter, 1990). For example, Gervai et al. (1995) found that parents of preschool-aged children who held traditional beliefs about gender tended to behave in gender-stereotypical ways with regard to performing both household labor and childcare. Furthermore, when fathers were more traditional in terms of their ideology, mothers engaged in more traditionally feminine household labor, even when mothers themselves did not express traditional ideological views. These findings suggest that while an individual's behaviors may reflect their beliefs about the roles of women and men, in some cases, beliefs held by one member of a couple may influence their partner's behavior. When these types of complex relationships between gender ideology and gendered behavior exist within a family unit, it is unclear what messages children may receive about the appropriate roles of women and men.

Other findings suggest that parents' ideology and behavior do not always align with one another. One explanation for this phenomenon could be that the financial pressures faced by many low-income and working-class couples require mothers to work outside of the home even 
when parents may value mothers' roles as full-time homemakers. Findings by Deutsch and Saxon (1998) support this notion, and suggest that the experience of engaging in a pattern of labor division that does not align with one's beliefs may be stressful. As a result, couples may employ strategies to reduce feeling negative emotions. These researchers interviewed heterosexual couples in which the husband was considered a "blue-collar" worker. Even when men and women appeared to be egalitarian in terms of their division of household labor, couples "maintained [their] traditional gender identities" and prevented marital conflict by adhering to three central beliefs about their families: first, that fathers occupy the status of "primary breadwinner"; second, that mothers work only out of financial necessity; and third, that mothers' central role in the family is that of a parent.

\section{Parents' Division of Childcare}

In addition to performing more household labor, women tend to perform more childcare than their husbands (Aldous et al., 1998; Gervai et al., 1995; Patterson et al., 2004). Specifically, mothers have been found to provide more physical and emotional care for their children than fathers, and to engage in specific childcare tasks, such as bathing and dressing children, more frequently than fathers (Moon \& Hoffman, 2008).

Even when both parents work full-time, mothers still perform more childcare; furthermore, it appears that fathers' recognition of a family labor imbalance is not necessarily related to their increased performance of childcare (Aldous et al., 1998). Previous research also suggests that heterosexual couples divide childcare less equally than lesbian parents do (Chan, Brooks, Raboy \& Patterson, 1998). There is some evidence that gender ideology can explain why heterosexual couples tend to divide childcare unequally. For example, in a study of father involvement utilizing data from the National Survey of Families and Households, egalitarian 
fathers tended to be more involved with their children than traditional fathers (Bulanda, 2004). Deutsch, Lussier and Servis (1993) also found that when fathers held more non-traditional beliefs about gender, they tended to provide more care for their infants. It appears, then, that more traditionally-minded husbands generally perform less childcare than their peers with more egalitarian values.

Contextual factors, such as financial hardship, may also play a role in how parents choose (or are forced) to divide childcare tasks. For example, in a sample of dual-earner, working-class families with one-year-olds, the division of childcare between parents was most equitable when parents worked opposite shifts (Meteyer \& Perry-Jenkins, 2010). These findings suggest that the ways in which parents divide labor may not necessarily reflect their ideological orientation, but rather external circumstances such as socioeconomic status and available resources.

However, Meteyer and Perry-Jenkins (2010) also found that couples tended to share childcare tasks more equally when mothers worked full-time outside the home, and when mothers reported lower gatekeeping behaviors (i.e., when mothers were less controlling of fathers' interactions with their children). These findings suggest that wives' encouragement may facilitate fathers' involvement in childcare (Deutsch et al., 1993).

Like research regarding the division of household labor, the literature on the division of childcare suggests that parents' gender ideology may be related to their gendered behavior in a variety of ways. In addition, contextual factors such as economic hardship may contribute to the ways in which parents divide childcare. As a result, children may receive a complex assortment of messages about gender through their parents' beliefs and behavior.

\section{Parents' Division of Paid Labor}


Human-capital theory has been used to describe heterosexual couples' division of paid and family labor (Aldous et al., 1998). This theory highlights gender-based power inequity that emerges when fathers' work schedules are prioritized over mothers' in decision-making surrounding the division of household and paid labor. Whether these decisions are made through verbal communication that children may overhear, or based upon unspoken assumptions about the appropriate roles of men and women, it is likely that children are influenced by labor division choices such as these. Indeed, a longitudinal investigation by Cunningham (2001b) found that the more time mothers spent in paid labor through the first year of their daughters' lives, the less stereotypically feminine housework their daughters performed as adults. Furthermore, because the observed effect was not mediated by mothers' work hours when daughters were 15 years old, Cunningham suggests that children are particularly attuned to messages about the division of gendered labor in early childhood.

Additional evidence for the lasting effects of mothers' participation in paid labor is provided by Fan and Marini (2000), who found that in a national sample of 14-22 year olds, there was a direct effect of mothers' employment on both sons' and daughters' gender-role attitudes eight years later. Mothers' employment during adolescence was positively associated with their children's reports of egalitarian beliefs as young adults.

In addition to previously cited studies suggesting that heterosexual couples tend to divide housework and paid labor in a stereotypically gendered manner (Chan et al., 1998; Moon \& Hoffman, 2008; Patterson et al., 2004; Perkins \& DeMeis, 1996), a study utilizing data from the National Longitudinal Survey of Youth found that for married White men, fatherhood was associated with an increase of 58 hours in annual time spent performing paid labor (Glauber \& Gozjolko, 2011). Interestingly, this increase was more than twice as strong for men with 
traditional ideologies than for men with egalitarian ideologies. For Black men with both traditional and egalitarian ideologies, there was no relationship between work hours and becoming a father. This study is unique in its consideration of parents' race, gender, ideology and behavior, and while the findings are compelling, additional research that considers all of these variables is necessary to expand upon the meaning of these findings.

More research is necessary in order to explore the relationship between parents' work behavior and their children's beliefs about gender. In addition to utilizing several common measures of parents' gendered behavior, the current study includes additional, unique measures that may allow for a more nuanced assessment of the relationship between parents' performance of paid labor and children's gender-role attitudes. I consider parents' self-reported work preferences for women (i.e., to what extent each parent prefers that the mother stay at home as opposed to work outside the home), as well as how traditionally masculine or feminine parents' occupations are. Together, these measures are expected to produce a comprehensive analysis of how children learn about gender through their parents' performance of paid labor and experiences at work.

\section{Traditionality of Parents' Occupations}

In addition to communicating about gender through their ideology and performance of family labor, parents transmit gendered messages to their children through the traditionality of their occupations (Fulcher, 2010) — that is, how stereotypically masculine or feminine their job is considered to be. Job traditionality is a unique factor to consider, as it can reflect a parent's interests and ideology. At the same time, education and other socioeconomic factors may impact a parent's access to certain types of jobs, and for some, the decision to take a stereotypically feminine or masculine position may not feel like much of a choice. Therefore, job traditionality 
may be considered an indicator of parental behavior, and in some cases an indicator of parental ideology as well. For the purpose of the current study, parents' job traditionality is treated as a behavioral variable, although it should be noted that children might acquire both implicit and explicit messages from the gendered nature of their parents' occupations.

Few studies have examined parents' job traditionality as it relates to children's genderrole attitudes, and in the empirical work on this topic, findings have been mixed. On the one hand, Fulcher (2010) measured the traditionality of parents' jobs based on the percentage of same-gendered people holding similar positions in the United States, but found no relationship between the traditionality of parents' occupations and the career aspirations of children aged 712. In addition, the types of jobs held by parents were not related to children's perceived selfefficacy regarding non-stereotypically gendered tasks.

Barak and colleagues (1991) also considered mothers' job traditionality as a predictor of their preschool-aged children's interest in gender stereotyped activities. These authors randomly recruited a diverse group of coders to rate job titles as stereotypically masculine or feminine, and found that mothers with more traditionally feminine occupations tended to have children with more stereotyped interests, regardless of children's gender. Interestingly, the traditionality of fathers' occupations did not appear to be related to their children's interests. Thus, the conflicting evidence surrounding the relationship between parents' job traditionality and children's genderrole attitudes merits further consideration.

\section{E. The Relationship Between Parents' Gender Ideology, Parents' Gendered Behavior, and Children's Gender-Role Attitudes}

A few studies have considered both parents' ideologies and gendered behaviors as predictors of their children's gender-role attitudes. For example, Fulcher et al. (2007) considered 
parents' sexual orientation, gender ideology and division of paid and unpaid labor as predictors of pre-schoolers' gender-role attitudes and occupational aspirations. This study also demonstrated a relationship between parents' division of labor and children's occupational goals, such that parents who divided labor across traditional gender lines tended to have sons who demonstrated interest in stereotypically masculine occupations, and daughters who demonstrated interest in stereotypically feminine occupations.

Importantly, Fulcher et al. (2007) found that parents' gender ideology and division of paid and unpaid labor, in combination, predicted children's gender-role attitudes. Interestingly, parents' ideologies were the best predictors of children's gender-role attitudes (such that more traditional parents had children with less flexible understanding of gender roles) while division of childcare was the best predictor of children's career interests (such that when mothers performed more childcare than fathers, children demonstrated more stereotypically gendered occupational interests). These findings suggest that parental ideology and behavior may be unique predictors of different aspects of children’s gender-role attitudes.

In one of the few longitudinal studies that has considered both parents' ideology and behavior as predictors of child outcomes, Cunningham (2001b) considered parental division of traditionally feminine and masculine household tasks, parents' education level, mothers' gender role attitudes, and the amount of time mothers spent in paid labor. Outcome variables included adult children's gender-role attitudes and beliefs about the ways in which traditionally feminine housework should be divided between male and female partners. Cunningham found that mothers' gender ideology, measured when children were one year old, was related to children's preferences for household labor division at age 18. In addition, Cunningham suggests that fathers' participation in housework tends to be more influential when children are old enough to 
participate in household chores themselves, and that paternal modeling during this time is "more important for intergenerational similarity than early behavior modeling” (Cunningham, 2001b). In other words, while mothers' ideology when children were one year old predicted their genderrole attitudes at age 18, fathers' gendered behavior did not emerge as a predictive factor until children were older.

An additional study by Cunningham (2001a) found that parents' gendered behaviors predicted child outcomes more consistently than parents' ideology. Notably, the division of household labor when children were one year old (as opposed to during the teenage years) predicted how children allocated household tasks at age 31 as married or cohabiting partners. Specifically, when fathers performed more stereotypically feminine household tasks in early parenthood, their adult sons showed a similar pattern of labor division with their partners. There was not a significant relationship between parents' early division of labor and daughters' allocation of household tasks as adults. However, when mothers' employment hours were added to the equation, it appeared that the more time mothers spent in paid labor when children were one- to four-years-old, the less relative portion of traditionally feminine household tasks daughters performed as adults.

Findings from Cunningham's studies have important implications for the current study. First, it appears that although mothers’ gender ideology may play a lasting role in the development of children's gender-role attitudes, overall, parents' gendered behaviors seem to be better predictors of child outcomes. It is unclear, however, what role fathers' ideology might play in their children's gender development processes. Finally, it appears that parents' implicit and explicit messages about gender may reach sons and daughters differently.

\section{F. The Role of Parent and Child Sex in Children's Development of Gender-Role Attitudes}


In Cunningham's (2001) studies, as well as several of the other studies reviewed, outcomes have differed based sex of the parent, sex of the child, or both. While it has been suggested that mothers and fathers expect different behavior from boys and girls (Fagot \& Hagan, 1991; Pagano et al., 2002) and engage differently with children based on their child's gender (Turner \& Gervai, 1995), it is also possible that boys and girls differ in terms of how they interpret parents' messages about gender (Gervai et al., 1995; Kulik, 2002).

In a longitudinal observational study of parents' interactions with 12-month-olds, 18month-olds, and 5-year-old children, mothers were found to give more instructions and directions to children than fathers, while fathers spent more time in "positive play interaction" than mothers did (Fagot \& Hagan, 1991). When children were 18 months, fathers tended to react less positively to boys engaging in play with stereotypically feminine toys (Fagot \& Hagan, 1991). This may suggest that ideologically traditional fathers are more enforcing of traditional behavior in children, and that fathers' communication about gender roles is directed more toward sons than daughters.

If this is indeed the case, how might fathers pass along ideological messages to their daughters? The findings on this topic are mixed. There is evidence that fathers and sons show stronger ideological agreement than fathers and daughters. In one such study, Kulik (2002) used measures of gender role stereotypes and occupational sex-typing to examine the intergenerational transmission of gender ideology from parents to adolescents. Boys tended to show more ideological similarity to their fathers than girls did, while mothers' ideologies did not appear to be related to their children's.

There is also evidence that points to a tendency for fathers and daughters to have more detached relationships. These findings suggest that as a result, fathers may be less influential 
figures for daughters in general (Aldous, et al., 1998; Carlson and Knoester, 2011; Kulik, 2002; Moon and Hoffman, 2008).

Similarly, Carlson and Knoester (2011) studied intergenerational transmission of gender ideology across different family structures, including single-mother and two-parent heterosexual families, as well as families with one biological parent and one stepparent. The authors found that mothers and sons tended to show more ideological similarity, while fathers' and daughters' beliefs diverged from one another. However, the conceptualization of gender ideology in this study is limited, as both parent and child ideology were measured through participants' level of agreement with three questions concerning the division of gendered labor between men and women.

Finally, in a study of communication about gender-related values between adolescents and college-aged young adults and their parents, Epstein and Ward (2011) found that the process of gender socialization within the family was similar for boys and girls. Given the mixed findings regarding the relationship between parent and child sex in the process of children's gender socialization, it is clear that more research is needed to understand how these factors may predict the ways in which children are influenced by parents' ideology. It would also be wise to consider other demographic aspects in future research, such as children's race, ethnicity and age (in addition to their sex), as these factors have been found to play a role in the ways in which parents teach children about individualist values and concern for others (Pagano et al., 2002).

\section{G. Limitations of Previous Studies}

Previous studies have tended to overlook the ways in which gender socialization of children may occur in two-parent families where both mothers and fathers have the potential to shape the child's development. It has been a common practice for researchers to either rely on 
mothers' reports of fathers' behavior (Fulcher, 2010) or to forego collecting data from fathers (e.g., Cunningham’s 2001a \& 2001b omission of fathers' gender ideology). This is a serious limitation, as literature that excludes fathers not only fails to demonstrate their potential contributions to children's gender development, but could also lead to over-estimation of mothers' contributions. The current study builds on previous findings to consider the potential for mothers' and fathers' ideologies and performance of gendered behavior to predict their children's gender-role attitudes in the context of two-parent, heterosexual families.

Methodological problems around the measurement of parents' gender ideology and behavior are also common among the studies reviewed. In some cases, gender ideology was assessed through responses to only a few items. For example, Cunningham (2001b) used only two items regarding beliefs about the division of household labor to measure mothers' ideology at the first wave of data collection, and five items to measure mothers' and young adult children's attitudes at the second time point. It may be difficult to obtain a broad understanding of ideology through this type of measurement.

In other cases, parents' gender ideology is measured through global assessment of beliefs about the roles of men and women in society—-for example, through the use of The Attitudes Towards Women Scale (Spence \& Helmreich, 1972; Spence \& Helmreich, 1973), which the current study also utilizes. Although this is a common measure, it is worth considering the beliefs that parents hold with regard to their own families in addition to their social values surrounding gender roles in addition to more global values. Some research suggests that beliefs about the roles of men and women in society are not necessarily reflected in the expectations a person has about gender roles in his or her own family (Hood, 1986; Perry-Jenkins \& Crouter, 1990). It is possible, for example, for a person to hold egalitarian views about men and women, 
but to prefer a more traditional arrangement in their daily lives. Thus, in addition to considering parents' gender ideology from a global perspective, the current study will examine mothers' and fathers' preferences regarding their own roles as well as their partners' roles within the family context.

Importantly, most studies that have considered predictors of children's gender-role attitudes have utilized cross-sectional data (Epstein and Ward, 2011; Fulcher, 2010; Kulik, 2002; Pagano, Hirsch, Deutsch, \& McAdams, 2002; Turner \& Gervai, 1995). However, a few longitudinal studies have highlighted the lasting effects of early parental influence on gender-role attitudes held by their offspring across the lifespan (Cunningham 2001a; Cunningham 2001b; Fan \& Marini, 2000), and specifically the importance of parents’ influence during the first year of life (Cunningham 2001a; Cunningham 2001b). Limited findings regarding how the effects of early predictors compare to those of concurrent predictors merit further exploration in this area.

\section{H. Research Questions}

The goal of the current study is to expand on previous findings by examining the relationship between (a) parents’ early and concurrent gender ideology and their children’s attitudes about gender, and (b) parents' early and concurrent gendered behaviors and their children's attitudes about gender. In addition, I explore: (c) whether parents' gender ideologies are a better predictor of children's gender-role attitudes than parents' gendered behaviors and (d) whether these relationships differ based on parent and child sex. In keeping with these goals, I ask the following questions:

Research Question 1: Are parents' (a) early gender ideologies (measured during the first year of parenthood) and (b) concurrent gender ideologies (measured when children are six years old) related to the gender-role attitudes held by their first grade children? 
Hypothesis 1: The majority of research on this relationship suggests that mothers' concurrent gender ideology will be significantly related to children’s gender-role attitudes at age six (Fulcher et. al, 2007; Fulcher, 2010; Sutfin et al., 2008). Although mothers' early ideology has also been related to older children's attitudes (Cunningham, 2001b), there is less research on the relative effects of mothers' ideology across time. In addition, while there is some evidence to suggest that fathers' concurrent ideology will be significantly related to children's gender-role attitudes (Fulcher et. al., 2007; Sutfin et. al., 2008), these findings are less robust than the findings regarding mothers' concurrent ideology. Finally, past research on the role of fathers' early ideology is too limited to inform the present study.

Research Question 2: Are parents' (a) early performance of gendered behaviors and (b) concurrent performance of gendered behaviors related to the gender-role attitudes held by their first grade children?

Hypothesis 2: Research suggests that mothers' early behavior will be significantly related to children’s gender-role attitudes (Cunningham, 2001a; Cunningham, 2001b; Fan \& Marini, 2000). There is not enough evidence to suggest that fathers' early behavior is related to children's gender-role attitudes; however, it is expected that fathers' concurrent behavior will be significantly related to child outcomes (Fulcher et al., 2007; Cunningham, 2001a; Cunningham, 2001b).

Research Question 3a: Which is a stronger predictor of children's gender-role attitudes: parents' gender ideologies or parents' gendered behaviors? 
Hypothesis 3a: Although studies that compare the relative effects of parents' ideology and gendered behavior report mixed findings (Fulcher et. al, 2007, Cunningham, 2001a), there is more evidence to suggest that parents' gendered behavior will significantly predict children's gender-role attitudes above and beyond the effects of parents' gender ideologies.

Research Question 3b: Do relationships between parents' gender ideologies and gendered behavior and children's gender-role attitudes differ based on child sex?

Hypothesis 3b: Although previous research has produced mixed findings about the roles of parent and child sex in the process of children's gender development, evidence suggests that (a) fathers' ideologies will be more closely related to sons' gender-role attitudes than daughters' (Kulik, 2002), and (b) mothers' and fathers' behaviors will predict both sons' and daughters' gender-role attitudes (Cunningham, 2001a; Cunningham, 2001b; Fulcher et al., 2007).

Exploratory Analyses: Previous studies leave many unanswered questions regarding the relative effects of parents' early and late ideologies and behaviors on boys' and girls' gender-role attitudes. For example, Fulcher et al. (2007) found that parents' concurrent ideologies predicted children's knowledge of sex stereotypes, while parents' concurrent division of childcare predicted children's interest in sex-stereotyped occupations. Importantly, however, this study did not include early parental predictors, and analyses did not take child sex into account. In Cunningham’s (2001a) study, fathers' early gendered behavior predicted their adult sons' division of labor, while mothers' early paid labor predicted adult daughters' division of household labor. Given the lack of clarity surrounding the combined influences of (a) early and late parental predictors, (b) 
relationships between parental predictors and multiple measures of children’s gender-role attitudes, and (c) relationships between parent and child sex, the current study will include exploratory analyses that attempt to answer the following question: which parental variables predict which measures of boys’ and girls’ gender-role attitudes? 


\section{CHAPTER II}

\section{METHODOLOGY OF THE PRESENT STUDY}

\section{$\underline{\text { A. Participants and Procedure }}$}

The sample for the present study was taken from The Work and Families Transition Project (Perry-Jenkins, Goldberg, Pierce, \& Sayer, 2007), a longitudinal study that followed working-class, heterosexual married or cohabiting couples and their children over a period of six years. Participants were dual-earner, working-class couples (defined as having earned an Associate's Degree or less). Couples expecting their first child were recruited for a larger longitudinal study through prenatal education classes at hospitals in Western Massachusetts prior to the birth of their first child.

Data for the current study was collected from parents at five time points across the first year of children's lives, and from parents and children approximately six years after the child's birth, as children were entering first grade. Parents were first interviewed individually in their homes: 1) during the wife's third trimester of pregnancy; 2) after the baby’s birth, but before the mother had returned to work; 3) approximately one month after mothers returned to work fulltime; 4) when babies were six months old (using a mail survey); and 5) when children were one year old. Scores for the “early predictors” of gender ideology and gendered behavior were averaged across time points during the first year. In addition, a six-year follow-up interview was conducted with both parents and children. During a face-to-face interview, children completed the Sex Roles Learning Inventory (SERLI), an interactive measure of gender-role attitudes. Parents completed “concurrent” measures of parental ideology and behavior.

The sample includes data from 109 couples. At the time of the first interview, mothers ranged in age from 17.65 - 40.81 years, with the average age being 27.43 years $(S D=4.82)$. 
Fathers ranged in age from $18.61-41.27$ years, with a mean age of 29.22 years $(S D=5.03)$. In terms of race, $95.4 \%$ of mothers $(n=104)$ and $90.8 \%$ of fathers $(n=99)$ identified as White. Two mothers and two fathers identified as African-American; one mother and two fathers identified as Latina or Latino, one father identified as Asian, four fathers identified as Mixed race, and two mothers and one father identified as "Other" in terms of ethnic categories.

In terms of education, the majority of mothers $(72.5 \% ; n=79)$ and fathers $(83.5 \% ; n=$ 91) held high school diplomas or the equivalent at the time of the first interview. Twenty-seven mothers (24.8\%) and 16 fathers (14.7\%) had completed an Associate's degree. Three mothers (2.8\%) and two fathers (1.8\%) had not completed high school.

At the time of the initial interview, mothers reported earning an average gross salary of $\$ 24,123(S D=\$ 10,309)$. The average income for fathers at this time was $\$ 31,028(S D=$ $\$ 11,204)$. At the time of the final interview, mothers' average gross income was $\$ 29,883$, ( $S D=$ $\$ 18,361)$, and the average income for fathers was $\$ 50,171$, $(S D=\$ 23,510)$. It should be noted that, given the nature of the sample, families sometimes reported experiencing multiple transitions in and out of employment (due to seasonal and temporary positions, for example). As a result, that these numbers may not accurately represent parents' consistent incomes. In addition, many parents reported working in more than one job, either short-term or long term.

Of the children who participated in the study, 62 were girls (56.9\%) and 47 were boys (43.1\%). Children ranged in age from 6.22 years to 7.50 years $(M=6.90, S D=.26)$.

\section{B. Measures and Variables}

Participants completed a number of standardized questionnaires related to each of the independent variables: parental global gender ideology, work preferences for mothers, and division of household labor, childcare and paid work hours. In addition, parents reported their 
job titles, which were used to calculate job traditionality scores based on data from the Bureau of Labor Statistics. The dependent variable, children's gender-role attitudes, was measured using a dynamic, interactive measure that assessed children's beliefs about sex stereotypes and their own gendered interests in multiple ways.

\section{Parents' Gender Ideology}

Parents' global gender ideology was assessed at two time points during the first yearduring the third trimester of pregnancy, and when children were six months old. Mothers and fathers each completed the Men's and Women's Roles questionnaire (Brogan \& Kutner, 1976), a 39-item inventory that asks respondents about their beliefs regarding prescribed gender roles and behaviors (see Appendix A). Participants responded to items (including "It is more important for a woman to keep her figure and dress fashionably than it is for a man”) on a 6-point Likert scale, where "1" indicated "Strongly Agree” and "6" indicated "Strongly Disagree." For the current sample, Chronbach’s alphas ranged from .43-.68 for women, and .59-.67 for men on this measure.

When children were six, The Attitudes Towards Women Scale (Spence \& Helmreich, 1972; Spence \& Helmreich, 1973) assessed parents’ gender ideology using a 4-point Likert scale that measures attitudes toward women’s and men's “rightful” roles in society (see Appendix B). Items included such prompts as "A woman should be as free as a man to propose marriage" and "The intellectual leadership of a community should be largely in the hands of men." Participants rated items from 1 (“Agree strongly”) to 4 (“Disagree strongly”). Approximately half of the items were then reverse coded, and participants' average scores were used to represent the extent to which they held traditional or egalitarian beliefs about the roles of women and men. Higher scores indicate more traditional values. This scale has been found to be both reliable (with 
Chronbach's alpha scores ranging from .78 to .85) and valid across samples (Nelson, 1988). For the current sample, Chronbach's alphas were .75 for women and .83 for men on this measure.

In addition, both men and women were asked about their preferences regarding women's involvement in paid labor at four time points during the first year, and when children were six (see Appendix C). Women were given the prompt, "While some individuals have a strong desire to work outside of the home, others would rather not. How do you feel about working now? Participants rated their attitude on a four-point Likert scale ranging from 1 "Strongly prefer to work" to 4 "Strongly prefer not to work".

\section{Parents' Gendered Behavior}

Parents' gendered behaviors were measured through questionnaires that assessed the division of household labor (Cowan \& Cowan, 1987) and childcare tasks (Barnett \& Baruch, 1987; Bouchard \& Lee, 2000). In addition, information was gathered about each parent's involvement in paid labor.

\section{a. Division of Household Labor}

Mothers and fathers each completed a questionnaire entitled Who Does What? (Cowan \& Cowan, 1987) at four time points during the first year, and also when children were six. This questionnaire measures each partner's perception of the proportion of traditionally feminine household tasks they perform relative to their spouse (see Appendix D). Participants were prompted with activities such as "Dishwashing” and "Laundry," and asked how often they performed the task in question. A 5-point scale was provided, where 1 indicated "Mostly or always my spouse/partner" and 5 indicated "Mostly or always me.” A reliability analysis produced Chronbach alphas ranging from .64 - .75 for mothers and .50 - .62 for fathers across 
four time points during the first year, during the first year, and .76 for mothers and .75 for fathers during the sixth.

\section{b. Division of Childcare Tasks}

To assess the division of childcare tasks performed by each parent, mothers and fathers completed a 15-item Childcare Responsibility inventory (Barnett \& Baruch, 1987) after their child's birth, one month after mothers returned to work, and when children were one year old (see Appendix E). On this questionnaire, respondents indicated the proportion of their contribution to childcare tasks relative to their spouse on a 5-point Likert scale, where 1 indicated "Mostly or always my spouse/partner" and 5 indicated "Mostly or always me.” Participants reported their relative contribution to tasks including "Feeding the baby," "Helping the baby learn new skills," and "Taking the baby to a doctor's appointment.” A reliability analysis produced Chronbach alphas ranging from $.83-.89$ for mothers, and $.76-.80$ for fathers on this measure across the first year of parenthood.

When children were six, parents completed the Childcare Involvement questionnaire (Bouchard \& Lee, 2000; see Appendix F). Using a 7-point Likert scale, mothers and fathers each reported how often they performed both daily and occasional childcare tasks, where 1 indicated “Never” and 7 indicated “Almost always” or "Every time.” Daily childcare tasks include activities such as helping their child with his or her morning routine or putting their child to bed in the evening, while occasional childcare tasks include such activities as staying home when their child is sick or helping their child clean his or her room. Higher scores on this measure indicated that more of the tasks were performed by the respondent than his or her spouse. A reliability analysis produced Chronbach alphas of .71 for mothers and .77 for fathers.

\section{c. Parents' Paid Labor}


Parents were asked to provide basic information about their work lives, including whether or not they were employed at the time of data collection, how many hours per week they spent in paid employment, and the title of their position. This information was collected for each parent at the following times: (1) when mothers returned to work; (2) when children were one year old, and (3) when children were six years old. For mothers and fathers, the "early work hours” variable was created by averaging reported work hours from both time points during the first year.

In addition, each partner's gross income was considered as an additional measure of work; however, because income and work hours were highly correlated with one another, only parents' work hours were included in analyses, as time spent in paid labor was thought to be more easily be observed by children.

\section{d. Traditionality of Parents' Occupations}

Parents' occupations were coded for how traditionally masculine or feminine they are. Continuous traditionality scores on a scale of 0-100 were assigned to each job based on data from the United States Department of Labor (2011) regarding the percentage of women who currently hold the same job title in the United States. The "early job traditionality" score was based on each parent's job title when children were one year old, and the "concurrent job traditionality” score was based on parents' job title when children were six.

\section{Children's Gender-Role Attitudes}

The SERLI (Edelbrock \& Sugawara, 1978) was used to assess children’s knowledge of sex role stereotypes and how flexible they feel when applying this knowledge to their own behavior. This measure consists of multiple subscales, including Sex Role Discrimination (Own Sex), which assesses the child's awareness of sex stereotypes related to members of their own 
sex, and Sex Role Discrimination (Opposite Sex), which relates to knowledge about sex stereotypes that pertain to members of the opposite sex. Children were shown pictures of objects (such as a hammer or a doll) and asked to identify the object as "for girls," "for boys," or "for

girls and boys.” Upon completion of this activity, children engaged in a forced-choice exercise in which they were asked to identify the gender-neutral objects as either feminine or masculine.

An additional subscale, Sex Role Preference (Adult Figures), gauges the child's interest in future sex-typed occupations. Participants were shown pictures of adults engaging in traditionally feminine or masculine occupational positions (such as teacher and firefighter, respectively) and asked to report how much they themselves would be interested in the occupation in question.

\section{Human Subjects}

The proposed study, which utilizes data from a larger longitudinal study, has been approved by the University of Massachusetts Amherst's Institutional Review Board. In accordance with guidelines for this approval, the ethical protocol for work with human subjects has been met. 


\section{CHAPTER III}

\section{FINDINGS}

\section{$\underline{\text { A. Descriptive data }}$}

Descriptive analyses for early and concurrent predictor variables are shown in Table 1. Paired sample $t$-tests were used to test for mean differences in mothers' and fathers' reports on early and concurrent predictor variables.

\section{Parents’ Gender Ideology}

$T$-test results revealed that mothers reported significantly more egalitarian views $(M=$ $5.30, S D=.45)$ than fathers $(M=4.88, S D=.59): t(2,106)=6.67, p<.001$ during the first year. There was also a significant difference between mothers' work preferences $(M=2.54, S D=.67)$ and fathers' work preferences for mothers $(M=2.72, S D=.58)$ during the first year of parenthood: $t(2,107)=-2.76, p<.01$. On average, fathers reported a greater preference towards having their wives work outside the home than mothers reported having for themselves.

When children were six years old, findings showed that mothers continued to report significantly more egalitarian global beliefs $(M=3.46, S D=.34)$ than their husbands $(M=3.27$, $S D=.44): t(2,93)=3.71, p<.001$. Mothers' reported work preferences $(M=2.61, S D=.95)$ did not differ significantly from their husbands’ preferences $(M=2.55, S D=.80)$ when children were six years old.

\section{Parents' Gendered Behavior}

Mothers reported performing significantly more feminine household tasks during the first year of parenthood $(M=3.96, S D=.49)$ than their husbands $(M=2.45, S D=.40): t(2,106)=$ 19.11, $p<.001$. Also, on the Childcare Responsibility questionnaire, mothers' average scores ( $M$ $=3.67, S D=.37)$ were significantly different from fathers' average scores $(M=2.56, S D=.25)$ : 
$t(2,107)=20.92, p<.001$, indicating that mothers reported performing a greater proportion of childcare tasks than their husbands during the first year of parenthood.

Mothers worked fewer hours in paid employment $(M=36.03, S D=10.05)$ than fathers $(M=45.67, S D=8.24): t(2,99)=-7.88, p<.001$ during the first year of parenthood. In addition, mothers' average job traditionality scores $(M=65.87, S D=24.96)$ differed significantly from fathers' $(M=24.88, S D=22.88): t(2,90)=11.89, p<.001$, suggesting that mothers tended to hold more traditionally female occupations than their husbands.

With regard to parents' gendered behavior when children were six, mothers continued to report performing a greater proportion of traditionally feminine household tasks than their husbands (mothers $M=4.10, S D=.58$; fathers $M=2.43, S D=.64$ ): $t(2,90)=14.23, p<.001$ ). In addition, mothers continued to report performing significantly more childcare $(M=5.29, S D=$ $.85)$ than their husbands $(M=3.85, S D=.88): t(2,90)=9.91, p<.001$ when children were six years old.

In year six, mothers spent significantly fewer hours per week in paid employment $(M=$ 33.81, $S D=13.24)$ than their husbands $(M=45.88, S D=11.91): t(2,81)=-5.09, p<.001$. Mothers continued to hold more traditionally female-dominated occupations than their husbands (mothers: $M=65.28, S D=25.16$ fathers: $M=28.88, S D=27.29): t(2,77)=7.29, p<.001)$.

\section{Relationships Among Predictor Variables}

Intercorrelations among predictor variables are displayed in Tables 2 and 3. Table 2 demonstrates that for mothers, early global gender ideology was positively correlated with work preferences (such that mothers who held more egalitarian values were more likely to prefer to work outside the home), and negatively correlated with performance of feminine household tasks 
and childcare (such that more egalitarian mothers performed fewer tasks relative to their partners).

For fathers, there was not a significant relationship between global gender ideology and work preferences for their wives. The relationship between fathers' global ideology and performance of both traditionally feminine housework and childcare appears to complement the findings for mothers: the more fathers reported holding egalitarian beliefs, the more feminine housework and childcare they reported performing relative to their spouses. The strongest correlations among early predictor variables emerged for mothers' and fathers reports for both feminine household tasks and childcare. For each spouse, more frequent performance of housework was positively associated with performance of childcare. In addition, the more tasks mothers reported performing in each of these domains, the less their husbands reported performing. Interestingly, the more hours mothers worked outside of the home, the less housework and childcare mothers did; however, the same relationships between household and paid labor were not significant for fathers.

As shown in Table 3, not all of the relationships found between year 1 predictors were replicated with year 6 predictor variables. Notably, mothers' concurrent global gender ideology was not significantly related to any other maternal predictor variable when children were six. Also in contrast to findings during the first year of parenthood, there was a significant positive relationship between fathers' concurrent global ideology and work preferences for their wives, such that the more fathers held egalitarian beliefs, the more they preferred that their wives work outside the home. However, relationships between partners' reported performance of both feminine housework and childcare remained relatively stable. 
Given that multiple indicators of both gender ideology and gendered behavior were assessed, and to retain greater power for the analyses, we used Principal Components Analysis (PCA) to create composite variables representing four substantive constructs: 1) Early Gender Ideology, 2) Early Gendered Behavior, 3) Concurrent Gender Ideology, and 4) Concurrent Gendered Behavior for each parent. Variables that assessed mothers' early gender ideology— specifically, mothers' global gender ideology and work preferences—-were used to create a principal component for mothers' early gender ideology. The same process was used for fathers' early gender ideology, and for each parents' concurrent gender ideology. For both mothers and fathers, a high score on the Gender Ideology scale represents more egalitarian views, while a low score represents more traditional views.

PCA was also used to create composites of gendered behaviors. Specifically, four variables that assessed each parent’s gendered behavior across a variety of domains (i.e., performance of traditionally feminine household tasks, performance of childcare tasks, average weekly hours in paid labor, and job traditionality) were used to create principal components for mothers and fathers at each time point. Scores on the original measures were recoded so that a high score represents more a more traditional division of labor. Specifically, for mothers, a high score on the Gendered Behavior PC scale represents more traditionally feminine behavior (i.e., housework, childcare, feminine paid labor), and less traditionally masculine behavior (i.e., hours spent in paid employment). For fathers, a high score on the Gendered Behavior PC scale represents less traditionally feminine behavior and more traditionally masculine behavior. Each of the four principal component variables were then used in all regression models.

Table 4 provides data for the relationships between each principal component variable. As shown in Table 4, there were significant relationships between each parent's ideology and 
behavior, such that the more egalitarian views they held, the less traditional behavior they reported. For each parent, the relationship between both ideology and behavior remained relatively stable over time. In addition, relationships between spouses' ideology and behavior were correlated at each time point.

\section{Children's Gender-Role Attitudes}

Table 5 provides descriptive data for three measures of children's gender-role attitudes: Sex Role Discrimination (Own Sex), Sex Role Discrimination (Opposite Sex), and Sex Role Preferences (Adult Figures). Boys’ scores on the Sex Role Discrimination (Opposite Sex) scale $(M=87.76, S D=17.16)$ differed significantly from girls’ scores $(M=87.08, S D=9.28)$, such that boys exhibited more knowledge about feminine sex role stereotypes, while girls exhibited less knowledge about masculine sex role stereotypes. There were no sex-based differences on the Sex Role Discrimination (Own Sex) or the Sex Role Preferences (Adult Figures) scales.

\section{B. Parents' Gender Ideology and Children's Gender-Role Attitudes}

Table 6 provides correlational data for the relationships between each PC predictor variable and all three of the child outcome variables. There was a significant positive association between mothers' early behavior and children's Sex Role Discrimination (Own Sex) such that the more traditional mothers' behaviors during children's first year of life, the more knowledge children of sex role stereotypes for members of their own sex. A significant negative association emerged between mothers' concurrent ideology and Sex Role Discrimination (Own Sex), indicating that the more mothers held egalitarian beliefs when children were six, the less knowledge children had about sex role stereotypes pertaining to members of their own sex. None of the predictor variables for mothers were related to children's scores on the Sex Role 
Discrimination (Opposite Sex) measure, meaning that mothers' ideology and behavior were not related to children's knowledge of sex role stereotypes about members of the opposite sex.

Mothers' early behavior was positively associated with children’s Sex Role Preferences (Adult Figures). The more mothers performed traditional tasks during the first year, the more children expressed interest in sex-stereotyped careers at age six.

Although fathers' ideology and behavior were not significantly related to Sex Role Discrimination (Own Sex) at either time point, there were significant negative associations between both fathers' early and concurrent ideology and children's scores on the Sex Role Discrimination (Opposite Sex) scale. The more fathers held egalitarian beliefs, the less knowledge children had about sex role stereotypes relating to members of the opposite sex. This association was strongest between fathers' early ideology and Sex Role Discrimination (Opposite Sex); the relationship between these variables at year 6 was only marginally significant.

Finally, fathers' early behavior was positively associated with children’s Sex Role Preferences (Adult Figures). The more traditional behavior fathers performed during the first year, the more children expressed interest in sex-stereotyped careers, although this relationship was only marginally significant.

Table 7 provides results for Research Question 1, which examines the relationships between mothers' and fathers' early and concurrent gender ideology and three indicators of children's gender-role ideology: Sex Role Discrimination (Own and Opposite Sex) and Sex Role Preferences (Adult Figures). In all models, analyses were conducted separately for mothers and fathers. Using hierarchical regression, early gender ideology was entered in Step 1 of the model and concurrent gender ideology was entered in Step 2. As shown in Table 7, for mothers, there 
was only one trend, with concurrent ideology predicting children’s Sex Role Discrimination

(Own Sex): $\beta=-.21, p<.10$. When mothers reported more egalitarian values, children showed less knowledge about sex role stereotypes as they relate to members of the child's own sex.

There were no significant relationships between fathers’ predictor variables and children's scores on the Sex Role Discrimination (Own Sex) measure. In contrast, fathers' early gender ideology predicted Sex Role Discrimination (Opposite Sex): $\beta=-.28, p<01$. This finding suggests that when fathers reported more egalitarian values, children showed less knowledge of sex role stereotypes as they relate to members of the opposite sex. Furthermore, fathers' early gender ideology predicted children's outcomes on this measure even after fathers' concurrent gender ideology was added to the model. There were no significant relationships between any parental ideology predictors and children’s scores on the Sex Role Preferences (Adult Figures) measure.

In sum, there were relatively few findings linking parents’ early or concurrent gender ideology to children's gender-role attitudes. In the next set of analyses, relationships between parents’ gendered behaviors and children’s attitudes are examined.

\section{Parents' Gendered Behavior and Children's Gender-Role Attitudes}

Table 8 provides results for Research Question 2, which examines the relationships between mothers' and fathers' early and concurrent gendered behavior and three measures of the dependent variable: Sex Role Discrimination (Own Sex), Sex Role Discrimination (Opposite Sex) and Sex Role Preferences (Adult Figures). In these analyses, no significant relationships were found between parental predictors and Sex Role Discrimination (Opposite Sex).

As shown in Table 8, mothers’ early behavior was a marginally significant predictor of children's Sex Role Discrimination (Own Sex): $\beta=.19, p<.10$. This finding suggests that when 
mothers reported engaging in more traditionally gendered behaviors during children’s first year of life, children showed more knowledge about sex role stereotypes as they relate to members of the child's own sex.

In addition, mothers' gendered behavior during the first year of children’s lives significantly predicted children's scores on the Sex Role Preferences (Adult Figures) measure: $\beta$ $=.36, p<.01$. In fact, when mothers' concurrent gendered behavior was added to the model, mothers' early gendered behavior continued to predict children's scores on this measure: $\beta=.34$, $p<.01$. This finding suggests that the more mothers engaged in traditional behavior during the child's first year of life, the more children demonstrated a desire to adhere to sex role stereotypes at six years old.

Fathers' gendered behavior was not related to children's scores on either of the Sex Role Discrimination measures. However, fathers' behavior during the first year was significantly related to children's scores on the Sex Role Preferences (Adult Figures) measure: $\beta=.25, p<$ .05. This finding suggests that the more fathers engaged in traditional behavior during the child's first year of life, the more children expressed an interest in sex-stereotyped professions when they were six years old.

In sum, these models suggest that both mothers’ and fathers' gendered behavior during the first year of life predict six-year-olds' gender-role attitudes. The following set of analyses test the combined influence of parents’ gender ideology and gendered behaviors on children’s gender-role attitudes.

\section{Relative Effects of Parents' Gender Ideology and Gendered Behavior on Children's}

\section{Gender-Role Attitudes}


The next set of analyses examined whether parents' gender ideology or gendered behavior were better predicts children's gender-role attitudes. Each of the analyses was conducted separately for mothers and fathers. Using hierarchical regression, early and concurrent gender ideology were entered in Step 1 of the model, and early and concurrent gendered behaviors were entered in Step 2. As shown in Table 9, for mothers, concurrent gender ideology was a marginally significant predictor of children’s Sex Role Discrimination (Own Sex): $\beta=$ $.23, p<.10$. In other words, the more mothers held egalitarian beliefs when children were six, the less knowledge children demonstrated regarding sex role stereotypes as they relate to the child's own sex. This relationship held up even when mothers' concurrent behavior was added to the model.

Turning to the outcome of Sex-Role Discrimination (Opposite Sex), one trend emerged for fathers, such that the combination of both early and concurrent gender ideology predicted children's scores on this measure at a marginally significant level, suggesting that the more egalitarian ideology fathers held, the less stereotypical views children had about the opposite sex (see Table 9).

With regard to children’s Sex Role Preferences (Adult Figures), mothers’ early behavior continued to be a significant predictor of children's scores on this measure: $\beta=.35, p<.01$. This finding suggests that the more traditional behavior mothers engaged in during the first year of life, the more children expressed interest in gender stereotyped occupations at age six. Similarly, for fathers, there was a marginally significant relationship between early behavior and Sex Role Preferences (Adult Figures): $\beta=.29, p<.10$, suggesting that when fathers engaged in more traditional behavior during their child's first year, the more children were interested in stereotyped occupations when they were six years old. 
Tables 10 summarizes the findings that relate to the role of child sex as a moderating variable in the relationship between parental ideology, parental gendered behavior and children's gender role attitudes. For ease of reporting, results are only displayed for the outcome variable Sex Role Discrimination (Own Sex), as no significant interactions emerged between predictor variables and child sex on either of the other outcome variables. Analyses were conducted separately for each parent. Using hierarchical regression, mothers’ and fathers' early and concurrent gender ideology and early and concurrent gendered behavior PCs were entered in Step 1 of the model, child sex was entered in Step 2, and interactions for child sex with each of the predictor variables were entered in Step 3.

As Table 10 illustrates, only one significant interaction emerged when child sex was added to the model. Mothers' concurrent behavior interacted with child sex in predicting children's scores on the Sex Role Discrimination (Own Sex) measure: $\beta=.51, p<.01$, meaning that when mothers' behaviors were more traditional, six-year-old boys tended to show less awareness of masculine sex stereotypes. When mothers' concurrent behavior was more traditional, girls showed more awareness of feminine sex stereotypes (see Figure 1).

\section{E. Exploratory Analyses}

Finally, exploratory analyses were conducted with the aim of identifying the best (trimmed) models that explain the greatest amount of variance in each of the three separate indicators of children's gender-role attitudes. This procedure involved including all eight parental predictors in Step 1 of the regression models, child sex in Step 2, and each potential interaction with child sex in Step 3. Given limitations in sample size, each interaction was tested in a separate model. Results are described separately for each measure of the dependent variable.

\section{Sex Role Discrimination (Own Sex)}


In the final trimmed model for Sex Role Discrimination (Own Sex), predictors explained $35 \%$ of the variance in children's scores on this measure (see Table 11). In this model, there was a trend indicating that mothers' early behavior interacted with child $\operatorname{sex}(\beta=.30, p<.10)$. As shown in Figure 2, mothers' early traditional behavior was related to girls demonstrating more knowledge of feminine stereotypes. In contrast, boys' knowledge of masculine sex stereotypes hardly changed based on mothers' behavior, indicating that mothers' early behavior was unrelated to their sons' attitudes about masculine behaviors.

Mothers' concurrent behavior also interacted with child sex $(\beta=.57, p<.01)$, such that the more mothers engaged in traditionally feminine behavior, the more knowledge girls demonstrated regarding feminine stereotypes. In contrast to the findings for mothers' early behavior, when mothers engaged in more traditional feminine behavior when children were six years old, boys showed less knowledge of masculine sex stereotypes (see Figure 3).

\section{Sex Role Discrimination (Opposite Sex)}

The best trimmed model for Sex Role Discrimination (Opposite Sex) predicted 15\% of

the variance in this outcome and was primarily explained by an interaction between fathers' early ideology and child sex $(\beta=.33, p<.05)$. The more traditional ideology fathers held during the first year, the more knowledge their sons demonstrated regarding feminine sex stereotypes. The more egalitarian fathers were during the first year, the less knowledge sons had about feminine sex stereotypes. No relationship emerged for fathers' early ideology and daughters' knowledge of masculine sex stereotypes (see Figure 4).

\section{Sex Role Preferences (Adult Figures)}

No significant interactions emerged between parental predictors and child sex with regard to children's Sex Role Preferences (Adult Figures). The final model for this outcome, which 
explained $27 \%$ of the variance, included all eight parental predictors (see Table 13). With regard to children's interest in stereotypically gendered careers, the strongest main effects emerged for mothers' early behavior $(\beta=.41, p<.05)$ and fathers' early ideology $(\beta=.39, p<.05)$. The more traditional behavior mothers performed during the first year, the more their children expressed interest in sex-stereotyped careers. For fathers, more egalitarian views in the first year predicted children's preferences for stereotypical careers.

Findings for Questions 1, 2, and 3, as well as findings for the exploratory models, are further discussed in the following section. 


\section{CHAPTER IV \\ DISCUSSION OF FINDINGS}

The present study explored relationships between parents’ early and concurrent gender ideology and gendered behavior and their children's gender-role attitudes at age six. Different findings emerged when examining relationships between parental gender ideology, parents’ gendered behaviors and children's scores on each of the three SERLI subscales: 1) Sex Role Discrimination (Own Sex); 2) Sex Role Discrimination (Opposite Sex); and 3)Sex Role Preferences (Adult Figures). Thus, for clarity, the following discussion is organized according to each separate subscale of children’s gender ideology.

\section{A. Sex Role Discrimination (Own Sex)}

The Sex Role Discrimination (Own Sex) measure assesses children’s knowledge of sex stereotypes that pertain to members of their own sex. Knowledge of these stereotypes was assessed through participation in an activity in which children were shown pictures of objects and asked to identify the items as being "for girls," "for boys," or "for girls and boys." Scores for Sex Role Discrimination (Own Sex) were determined by the extent to which girls identified stereotypically feminine objects as being “for girls," and boys identified stereotypically masculine objects as being "for boys."

It was hypothesized that mothers’ concurrent gender ideology would be significantly related to children's gender-role attitudes at age six (Fulcher et. al, 2007; Fulcher, 2010; Sutfin et al., 2008), more so than early ideology, in part, because there is simply less research on the relative effects of mothers’ early ideology versus concurrent attitudes. Partial support was found for this hypothesis: a trend emerged in the initial models for mothers' concurrent ideology as a predictor of children's scores on the Sex Role Discrimination (Own Sex) measure with more 
egalitarian mothers having children with less rigid ideas about the expected behavior of children of their own sex. This finding disappeared in the final model, however, suggesting that mothers' ideology was not a predictor of children's knowledge of sex stereotypes regarding members of their own sex.

It was also hypothesized that mothers' early behavior would be significantly related to children's gender-role attitudes (Cunningham, 2001a; Cunningham, 2001b; Fan \& Marini, 2000). In the initial models, only one marginally significant finding for the relationship between mothers' early behavior and children’s scores on the Sex Role Discrimination (Own Sex) emerged. Further analyses revealed that these effects were conditional based on the sex of the child. Specifically, interactions between mothers' early and concurrent behavior and child sex were the best predictors of children's knowledge of sex stereotypes regarding members of their own sex. Girls demonstrated more knowledge of feminine sex stereotypes when their mothers engaged in more traditional behavior during both the first year of life and at age six. For boys, mothers early behavior appeared to have no effect, however, by the age of six boys showed less knowledge of masculine behavior when their mothers took on more traditional behaviors.

These findings suggest that mothers are the primary imparters of knowledge about feminine behavior for girls, and masculine behavior for boys. In other words, it appears that children take cues from their mothers in determining what behaviors are appropriate for boys and for girls. This notion is supported by previous findings that women provide more physical and emotional childcare than their husbands (Aldous et al., 1998; Gervai et al., 1995; Moon \& Hoffman, 2008); Patterson et al., 2004). It is likely that in the process of receiving more care from their mothers, children also receive gendered messages. 
Data from the current study suggest that girls tend to develop beliefs about what constitutes appropriate behavior for girls and women by observing the behavior that their mothers model. However, the process by which boys learn about masculine stereotypes from their mothers is less clear. Perhaps the finding that more traditional mothers tended to have sons with less knowledge of masculine sex stereotypes has less to do with mothers' behavior, and more to do with what goes on at the family level when mothers are responsible for more traditionally feminine tasks. For example, if traditional mothers are married to men who also perform more traditionally gendered behavior (e.g., spending more time in paid labor and therefore less time at home), boys' lack of knowledge about masculine sex stereotypes may be better explained by the absence of consistent exposure to their fathers. Indeed, previous literature suggests that heterosexual couples tend to divide labor across traditionally gendered lines (Perkins \& DeMeis, 1996; South \& Spitze, 1994), and that one partner's beliefs may inform the ways in which a couple divides gendered labor (Gervai et al., 1995).

If it is indeed the case that children learn about sex stereotypes by observing the behavior parents model, it would follow that children look to their same-sex parent as the primary model for sex-appropriate behavior. Social cognitive theory supports the idea that modeling plays a crucial role in children's ability to process and apply knowledge regarding differences between males and females (Bussey \& Bandura, 1999; Martin \& Ruble, 2009). The concept of learning by example is central to this theory, and could explain the relationship between girls' knowledge of feminine sex role stereotypes and their mothers' performance of traditionally feminine tasks. At the same time, the interaction between cognitive and social and environmental cues may explain boys' scores on this measure. Although boys and girls may engage in similar cognitive processes as they develop understanding of sex-appropriate behavior, if the availability of a 
same-sex adult model is different for boys and girls, their learning processes would differ as a result of differential relationships between the internal (cognitive) and external (social) worlds. Future research should examine the role of both father and mother involvement in children's lives to address these hypotheses.

It was also predicted that fathers' concurrent ideology would be significantly related to children’s gender-role attitudes (Fulcher et. al., 2007; Sutfin et. al., 2008)—although these findings are less robust than the findings regarding mothers' concurrent ideology—and that fathers' ideologies would be better predictors of sons’ attitudes than daughters' attitudes (Kulik, 2002). However, no relationships between any paternal predictors and children's scores on Sex Role Discrimination (Own Sex) were found. Finally, it was expected that parental behavior would predict children's gender-role attitudes above and beyond the effects parental ideology regardless of parent and child sex. With regard to children's knowledge of stereotypes about members of their own sex, partial support was found for this hypothesis: indeed, mothers' early and concurrent behavior were better predictors of children's attitudes on this measure than mothers' ideology at either time point, but the same finding did not emerge for fathers. Similar to Cunningham's (2001a, 2001b) findings, our results highlight the importance of parents' behavior during the first year as predictors of young children's gender ideology. Cunningham's work would also suggest that the current findings could hold up across an extended period of time and explain behavior well into young adulthood.

\section{B. Sex Role Discrimination (Opposite Sex)}

The Sex Role Discrimination (Opposite Sex) measure assesses children’s knowledge of sex stereotypes that pertain to members of the opposite sex. Knowledge of these stereotypes was assessed through participation in the same activity described above, in which children were 
shown pictures of objects and asked to identify the items as being "for girls," "for boys," or "for girls and boys.” Scores for Sex Role Discrimination (Opposite Sex) were determined by the extent to which girls identified stereotypically masculine objects as being “for boys,” and boys identified stereotypically feminine objects as being “for girls.”

No support was found for the hypotheses that mothers' gender ideology or gendered behaviors were related to children's gender-role attitudes at age six. It was also predicted that fathers' concurrent ideology would be significantly related to children’s gender-role attitudes (Fulcher et. al., 2007; Sutfin et. al., 2008). Again, no support was found for this hypothesis. In fact, the only predictor that significantly predicted children’s Sex Role Discrimination (Opposite Sex) was fathers' early ideology. Specifically, boys demonstrated more knowledge of feminine sex stereotypes when their fathers held more traditional ideology during the first year, and less knowledge of feminine sex stereotypes when their fathers were more egalitarian. The same relationship did not emerge for girls.

Past research offers some support for the finding that fathers’ ideology is more closely related to sons’ attitudes than to daughters’ attitudes (Kulik, 2002). Research suggests that traditional fathers are more enforcing of gender-stereotyped behavior for sons than for daughters (Fagot \& Hagan, 1991). This might explain why a significant finding emerged between fathers’ early ideology and boys’ knowledge of feminine sex stereotypes: if traditional fathers caution their sons against engaging in feminine behavior, it would hold that sons of traditional men have more knowledge of these feminine stereotypes than sons of egalitarian men. Furthermore, because fathers have been found to react less positively to 18-month-old boys’ play with stereotypically feminine toys than with stereotypically masculine toys (Fagot \& Hagan, 1991), it is possible that fathers communicate their gendered preferences even earlier in their children's 
lives, which would explain why fathers' early ideology predicted boys' attitudes on this scale above and beyond the effects of fathers' concurrent ideology.

This finding regarding the role of fathers' early ideology in predicting boys' gender-role attitudes at age six is particularly compelling because relatively few studies have considered the role of fathers' gender ideology as it relates to children's gender development. Longitudinal studies that have examined the role of early ideology in predicting children's attitudes has only included measures of mothers' ideology (Cunningham, 2001b), so the potential for fathers' ideology to inform their children's long-term beliefs has been virtually unexamined. Thus, findings from the present study should be used to inform future hypothesis-driven longitudinal research that follows fathers and their children.

\section{Sex Role Preferences (Adult Figures)}

This measure of children's gender-role attitudes assesses children's interest in sexstereotyped occupations. Children's preferences for traditionally feminine versus traditionally masculine careers were assessed through an activity in which children were shown pictures of adults engaging in behaviors associated with stereotypical occupations (e.g., firefighter, teacher) and asked to report how much they themselves would be interested in the depicted career.

With regard to this measure, no support was found for the hypotheses that mothers' or fathers' concurrent ideology would predict children's attitudes. Initial models showed that mothers' early behavior significantly predicted children's views of adult sex-typed occupations. Fathers' early behavior was also a marginally significant predictor of children's career preferences in initial models. However, the final model showed that mothers' early behavior continued to predict children's career preferences, but fathers' early ideology emerged as the other significant predictor. The more traditional behavior mothers performed during the first 
year, the more their children expressed interest in sex-stereotyped careers. For fathers, more egalitarian views in the first year predicted children's preferences for stereotypical careers. It is unclear why fathers' egalitarian views and mothers' traditional behavior would predict children's interest in traditionally gendered careers. This model suggests that a unique relationship exists between mothers' early behavior and fathers' ideology as it relates to children's gender-role attitudes, and it is possible that the relationship between fathers' egalitarian views and children's traditional preferences could be explained by additional variables related to the relationship between mothers' behavior and fathers' ideology. For example, it is possible that in families where fathers' ideas about the appropriate roles for women diverge from the behaviors their wives perform on a regular basis, children receive different types of messages about gender than children whose parents' ideology and behavior align more neatly.

Findings for this measure provide support for the hypothesis that mothers' early behavior would predict children's attitudes (Cunningham, 2001a; Cunningham, 2001b; Fan \& Marini, 2000) above and beyond the effects of mothers' ideology. However, there was no support for the hypothesis that fathers' concurrent behavior would predict children's attitudes. These findings support previous research that emphasizes the importance of mothers' behavior during the first year on children's gender development (Cunningham, 2001a; Cunningham, 2001b; Fan \& Marini, 2000). Interestingly, in one of the few studies to consider the relationship between parents' behavior and children's attitudes by using the Sex Role Preferences (Adult Figures) measure of the SERLI, Fulcher and colleagues (2007) found that when mothers of six-year-olds performed more childcare than fathers, children expressed more interest in traditional occupations. Findings from the current study suggest that if Fulcher and colleagues had 
controlled for parents' early behavior, parents' division of childcare in the first year of life might explain children's attitudes above and beyond the effects of parents' concurrent behavior.

Modeling could explain the role that mothers' early behavior plays in how children think about their future occupations. Unlike findings for the present study regarding Sex Role Discrimination, in which modeling of the same-sex parent was important for children's knowledge of sex stereotypes, the findings that emerged regarding children's interest in sexstereotyped occupations indicate that boys and girls attend to implicit and explicit messages from both parents as they develop visions of their own roles in the world. In this case, the concept of learning by example does not appear to be related to the match between parent and child sex, as it does in the processes of learning about gendered expectations for boys and girls. In fact, children's integration of cognitive and social cues may work somewhat differently when the process at hand involves picturing themselves engaging in a gendered activity (e.g., becoming a teacher or firefighter).

In sum, findings from the current study suggest that in general, mothers' and fathers' behavior—particularly during the first year of children's lives—are better predictors of children's gender-role attitudes than parents' ideology. The exceptions, however, were the finding that fathers' early ideology predicted sons' knowledge of feminine sex stereotypes, and that fathers' egalitarian values during the first year predicted children's traditional attitudes at age six. In addition, parent sex appeared to play a role in children's acquisition of knowledge about sex stereotypes, but the relationship between parent sex and child sex did not appear to make a difference with regard to children's interest in sex-typed occupations.

In terms of understanding the importance of parents' behavior and ideology during the first year of children's lives (relative to concurrent measures), the methodological approach of 
the current study should be considered. Because data was collected across year one and at year six, parents' behavior and ideology during year one represents the construct of early parental modeling. It is possible, however, that early data is indicative of parents' ideology and behavior across the early years (i.e., years one through five), and that exposure to parental ideology and behavior across time would more accurately explain the relationship between these variables and children's gender-role attitudes. In other words, it is possible that parents' early modeling can best be understood in terms of children's learning across the first five or six years, as opposed to children's learning during the first year of life. From this perspective, it would follow that as children enter first grade — a transition that often involves exposure to peers for longer and more frequent periods of time--the importance of early learning about gender that occurs within the context of the family becomes salient in terms of how children demonstrate gender-role attitudes. Thus, future longitudinal research could assess parental ideology and behavior annually across children's first years.

The current study is unique in that it consists of working-class, predominantly White heterosexual parents and their children. The nature of this sample may have influenced findings in a variety of ways. First, economic hardship may shape the ways in which parents divide household and paid labor. It is possible that as a result, parents' gendered behavior as it is measured in the current study does not map onto parents' ideology, which can cause strain at both the individual level and between partners (Deutsch \& Saxon, 1998). In addition, it is possible that findings may differ across racial, ethnic, and religious backgrounds (Kroska \& Elman, 2009). For example, Glauber and Gozjolko (2011) found that during the transition to parenthood, White fathers with traditional ideologies spent significantly more time in paid labor than White men with more egalitarian views, but there was no relationship between ideology and 
work hours for Black fathers. These findings suggest that race, gender, ideology and behavior may be uniquely related for parents, and it is possible that the nuances of these relationships could impact the messages that children receive about gender. In addition, Kroska and Elman (2009) found that when parents developed more traditional religious beliefs over time, their gender ideologies also become more traditional. It is unclear how parents' shifting ideologies might impact children's gender-role attitudes, and whether children would be more or less impacted by this type of ideological shift during particular developmental stages.

Family structure and parental sexual orientation may also play unique roles in shaping implicit and explicit communication about gender (Carlson \& Knoester, 2011; Patterson et al., 2004). For example, Patterson and colleagues (2004) found that lesbian couples tend to divide both paid and unpaid labor more evenly than heterosexual couples. Furthermore, Goldberg, Kashy and Smith (2012) found that 2-4 year old children of lesbian and gay couples demonstrated less interest in sex-stereotyped play than their peers with heterosexual parents. It is likely that difference in parents' ideology and behavior across diverse family structures lead to different outcomes in terms of how children develop gender-based beliefs and interests.

There is clearly a great deal more to understand about the influences that shape children's development. The longitudinal nature of the current study, as well as its attention to both maternal and paternal predictors, make this a unique and robust exploration of the relationship between parents' early and concurrent ideologies and behaviors and children's gender-role attitudes. Future research can build from the exploratory findings presented in the present study, and extend the exploration of early vs. concurrent parental variables across an extended period of time. 
Table 1: Descriptive statistics for mothers' and fathers' early and concurrent predictors of children's gender-role attitudes.

\begin{tabular}{|c|c|c|c|c|}
\hline & $N$ & Mean & $S D$ & Range \\
\hline \multicolumn{5}{|l|}{ Mothers } \\
\hline \multicolumn{5}{|l|}{ Year 1 Predictors } \\
\hline Gender ideology & 109 & $5.30^{*}$ & .45 & $3.84-6.00$ \\
\hline Work preferences & 109 & $2.54^{*}$ & .67 & $1.00-4.00$ \\
\hline Fem. HHT & 108 & $3.96^{*}$ & .49 & $2.94-4.88$ \\
\hline CCT & 109 & $3.67^{*}$ & .37 & $3.02-4.67$ \\
\hline Work hours & 104 & $36.03^{*}$ & 10.05 & $2.00-56.50$ \\
\hline Job traditionality & 98 & $65.87^{*}$ & 24.96 & $4.00-96.00$ \\
\hline \multicolumn{5}{|l|}{ Year 6 Predictors } \\
\hline Gender ideology & 104 & $3.46^{*}$ & .34 & $2.13-4.00$ \\
\hline Work preferences & 107 & 2.61 & .95 & $1.00-4.00$ \\
\hline Fem. HHT & 97 & $4.10^{*}$ & .58 & $2.88-5.00$ \\
\hline CCT & 101 & $5.29^{*}$ & .85 & $3.46-7.00$ \\
\hline Work hours & 94 & $33.81^{*}$ & 13.24 & $0.00-58.00$ \\
\hline Job traditionality & 93 & $65.28^{*}$ & 25.16 & $4.00-97.00$ \\
\hline \multicolumn{5}{|l|}{ Fathers } \\
\hline \multicolumn{5}{|l|}{ Year 1 Predictors } \\
\hline Gender ideology & 107 & 4.88 & .59 & $2.86-5.96$ \\
\hline Work preferences & 108 & 2.72 & .58 & $1.00-4.00$ \\
\hline Fem. HHT & 108 & 2.45 & .40 & $1.58-3.41$ \\
\hline CCT & 108 & 2.56 & .25 & $1.83-2.98$ \\
\hline Work hours & 101 & 45.67 & 8.24 & $19.00-74.00$ \\
\hline Job traditionality & 96 & 24.88 & 22.88 & $1.00-87.00$ \\
\hline \multicolumn{5}{|l|}{ Year 6 Predictors } \\
\hline Gender ideology & 94 & 3.27 & .44 & $1.33-3.93$ \\
\hline Work preferences & 87 & 2.55 & .80 & $1.00-4.00$ \\
\hline Fem. HHT & 92 & 2.43 & .64 & $1.38-4.50$ \\
\hline CCT & 92 & 3.85 & .88 & $2.08-6.64$ \\
\hline Work hours & 94 & 45.88 & 11.91 & $0.00-76.00$ \\
\hline Job traditionality & 90 & 28.88 & 27.29 & $1.00-93.00$ \\
\hline
\end{tabular}

Note. ${ }^{*} p<.05$ indicates that mothers' average scores differed significantly from their husbands’ at the same

time point. High scores on global gender ideology indicate more egalitarian beliefs. High scores on work

preferences indicate stronger preferences for mothers to work outside the home. High scores on traditionally

feminine household tasks (Fem. HHT) and childcare tasks (CCT) indicate more frequent performance of tasks

relative to one's partner. Job traditionality scores are calculated based on the number of women in the U.S. who

hold the same job title, according to the Bureau of Labor Statistics (2010). 
Table 2: Intercorrelations between mothers' and fathers' early predictors of children's gender-role attitudes.

\begin{tabular}{|c|c|c|c|c|c|c|c|c|c|c|c|c|}
\hline & 1 & 2 & 3 & 4 & 5 & 6 & 7 & 8 & 9 & 10 & 11 & 12 \\
\hline \multicolumn{13}{|l|}{ Mothers } \\
\hline 1. Global GI & & $.19^{*}$ & $-.26^{* *}$ & $-.29^{* *}$ & .08 & .02 & $.24^{*}$ & .06 & $.27^{* *}$ & .12 & -.07 & .07 \\
\hline 2. Work Prefs & & & -.10 & $-.16^{+}$ & .03 & .05 & -.09 & $.29^{* *}$ & -.00 & .06 & $.18^{+}$ & .15 \\
\hline 3. Fem. HHT & & & & $.60^{* * *}$ & $-.33^{* *}$ & .08 & $-.21^{*}$ & -.04 & $-.69^{* * *}$ & $-.29^{* *}$ & .04 & .08 \\
\hline 4. CCT & & & & & $-.37^{* * *}$ & .08 & $-.19^{*}$ & -.07 & $-.31^{* *}$ & $-.52^{* * *}$ & -.01 & -.09 \\
\hline 5. Work Hours & & & & & & $-.17^{+}$ & .02 & .08 & $.19^{+}$ & $.21^{*}$ & .11 & $-.18^{+}$ \\
\hline 6. Job trad. & & & & & & & -.04 & -.03 & -.09 & .04 & .03 & .02 \\
\hline \multicolumn{13}{|l|}{ Fathers } \\
\hline 7. Global GI & & & & & & & & .13 & $.29^{* *}$ & $.16^{+}$ & -.15 & $.23^{*}$ \\
\hline 8. Work Prefs & & & & & & & & & .04 & $.19^{* *}$ & -.03 & .16 \\
\hline 9. Fem. HHT & & & & & & & & & & $.41^{* * *}$ & -.09 & .02 \\
\hline 10. СCT & & & & & & & & & & & -.11 & .02 \\
\hline 11. Work Hours & & & & & & & & & & & & $\begin{array}{l}.02 \\
-.20^{+}\end{array}$ \\
\hline 12. Job trad. & & & & & & & & & & & & \\
\hline
\end{tabular}

Note ${ }^{+} p<1.0 ;{ }^{*} p<.05 ;{ }^{* *} p<.01,{ }^{* * *} p<.001$. GI = Gender ideology; Work Prefs = work preferences for mothers; Fem. HHT = performance of traditionally feminine household tasks (relative to spouse); CCT = performance of childcare tasks (relative to spouse); Work Hours = average weekly hours spent performing paid labor; Job trad = job traditionality. 
Table 3: Intercorrelations between mothers' and fathers' concurrent predictors of children's gender-role attitudes.

\begin{tabular}{|c|c|c|c|c|c|c|c|c|c|c|c|c|}
\hline & 1 & 2 & 3 & 4 & 5 & 6 & 7 & 8 & 9 & 10 & 11 & 12 \\
\hline \multicolumn{13}{|l|}{ Mothers } \\
\hline 1. Global GI & & .08 & -.16 & -.12 & .09 & .03 & $.24^{*}$ & .15 & $.21^{*}$ & .09 & .12 & .06 \\
\hline 2. Work Prefs & & & -.09 & -.09 & $.18^{+}$ & .13 & .08 & $.28^{* *}$ & .16 & .08 & .09 & .09 \\
\hline 3. Fem. HHT & & & & $.29^{* *}$ & -.18 & -.04 & $-.28^{* *}$ & -.10 & $-.67^{* * *}$ & $-.40^{* * *}$ & $.36^{* * *}$ & -.18 \\
\hline 4. ССТ & & & & & $-.20^{+}$ & -.01 & -.04 & -.06 & $-.29^{* *}$ & $-.20^{+}$ & $.19^{+}$ & -.16 \\
\hline 5. Work Hours & & & & & & $-.18^{+}$ & $.21^{+}$ & .19 & $.25^{*}$ & .16 & -.12 & -.08 \\
\hline 6. Job trad. & & & & & & & -.00 & .07 & .04 & .03 & .00 & -.18 \\
\hline \multicolumn{13}{|l|}{ Fathers } \\
\hline 7. Global GI & & & & & & & & $.26^{*}$ & $.18^{+}$ & $.38^{* * *}$ & $-.25^{*}$ & $.18^{+}$ \\
\hline 8. Work Prefs & & & & & & & & & .17 & $.26^{*}$ & -.11 & .01 \\
\hline 9. Fem. HHT & & & & & & & & & & $.28^{* *}$ & $-.32^{* *}$ & $.26^{*}$ \\
\hline 10. ССТ & & & & & & & & & & & $-.22^{*}$ & $.23^{*}$ \\
\hline 11. Work Hours & & & & & & & & & & & & -.15 \\
\hline 12. Job trad. & & & & & & & & & & & & \\
\hline
\end{tabular}

Note ${ }^{+} p<1.0 ;{ }^{*} p<.05 ;{ }^{* *} p<.01,{ }^{* * *} p<.001$. GI = Gender ideology; Work Prefs = work preferences for mothers; Fem. HHT = performance of traditionally feminine household tasks (relative to spouse); CCT = performance of childcare tasks (relative to spouse); Work Hours = average weekly hours spent performing paid labor; Job trad = job traditionality. 
Table 4: Intercorrelations between principal component variables representing mothers' and fathers' early and concurrent gender ideology and gendered behavior.

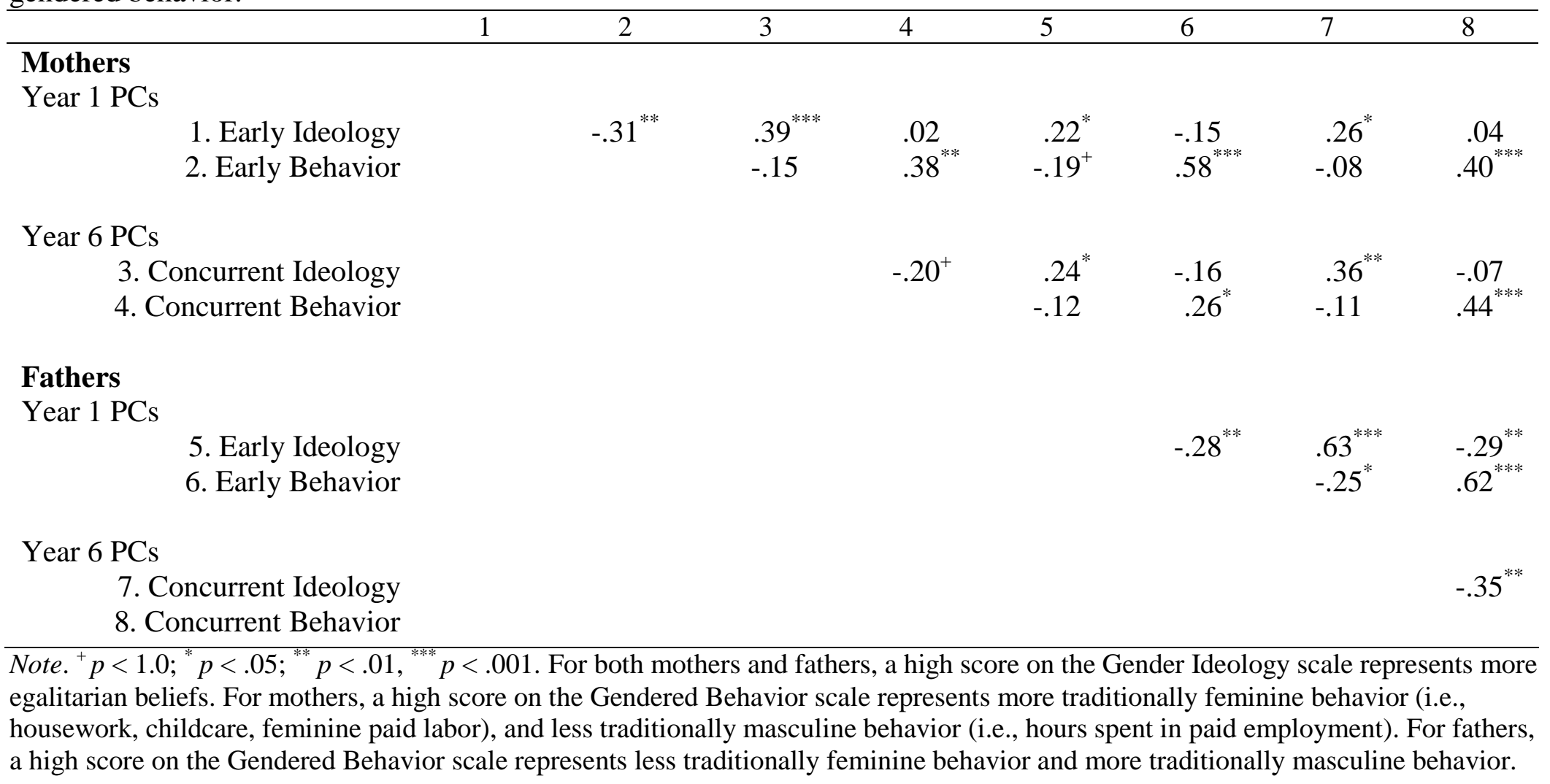


Table 5: Children’s gender-role attitudes.

$N \quad$ Mean $\quad S D \quad$ Range

Sex Role Discrimination (Own Sex)

$\begin{array}{rcccc}\text { Full sample } & 105 & 93.05 & 8.67 & 60-100 \\ \text { Boys } & 43 & 93.26 & 7.78 & 70-100 \\ \text { Girls } & 61 & 92.95 & 9.37 & 60-100\end{array}$

\section{Sex Role Discrimination (Opposite Sex)}

$\begin{array}{rrrrr}\text { Full sample } & 108 & 87.30 & 13.07 & 10-100 \\ \text { Boys } & 45 & 87.76^{*} & 17.16 & 10-100 \\ \text { Girls } & 62 & 87.08^{*} & 9.28 & 50-100\end{array}$

\section{Sex Role Preference (Adult Figures)}

$\begin{array}{rrrrr}\text { Full sample } & 104 & 56.88 & 12.78 & 27-80 \\ \text { Boys } & 43 & 57.19 & 13.31 & 29-80 \\ \text { Girls } & 61 & 56.66 & 12.50 & 27-80\end{array}$

Note. ${ }^{*} p<.05$ indicates that boys’ average scores differed significantly from girls’ on the same measure. The Sex Role Discrimination subscale measures children's awareness of sex stereotypes through the use of an activity in which children are asked to classify sex-stereotyped objects as being "for girls" or "for boys." A high score on the Sex Role Discrimination (Own Sex) measure indicates more knowledge about sex role stereotypes as they relate to members of the child's own sex, while a high score on the Sex Role Discrimination (Opposite Sex) measure indicates more knowledge about sex role stereotypes as they relate to members of the child's opposite sex. The Sex Role Preference (Adult Figures) subscale measure children's interest in gender-

stereotyped careers. A high score on this subscale suggests more desire to adhere to cultural stereotypes. 
Table 6: Correlations between principal component variables representing mothers' and fathers' early and concurrent gender ideology and gendered behavior and children's gender-role attitudes.

\begin{tabular}{|c|c|c|c|}
\hline & $\begin{array}{c}\text { Sex Role Discrimination } \\
\text { (Own Sex) }\end{array}$ & $\begin{array}{c}\text { Sex Role Discrimination } \\
\text { (Opposite Sex) }\end{array}$ & $\begin{array}{c}\text { Sex Role Preferences } \\
\text { (Adult Figures) }\end{array}$ \\
\hline \multicolumn{4}{|l|}{ Mothers } \\
\hline \multicolumn{4}{|l|}{ Year 1 PCs } \\
\hline Early Ideology & -.14 & -.07 & .05 \\
\hline Early Behavior & $.21^{*}$ & .04 & $.24^{*}$ \\
\hline \multicolumn{4}{|l|}{ Year 6 PCs } \\
\hline Concurrent Ideology & $-.24^{*}$ & -.04 & -.09 \\
\hline Concurrent Behavior & .12 & .02 & .20 \\
\hline \multicolumn{4}{|l|}{ Fathers } \\
\hline \multicolumn{4}{|l|}{ Year 1 PCs } \\
\hline Early Ideology & -.14 & $-.23^{*}$ & .05 \\
\hline Early Behavior & .16 & .06 & $.20^{+}$ \\
\hline \multicolumn{4}{|l|}{ Year 6 PCs } \\
\hline Concurrent Ideology & -.09 & $-.18^{+}$ & -.05 \\
\hline Concurrent Behavior & .15 & .09 & .16 \\
\hline
\end{tabular}

Note. ${ }^{+} p<1.0 ;{ }^{*} p<.05$. For both mothers and fathers, a high score on the Gender Ideology scale represents more egalitarian beliefs. For mothers, a high score on the Gendered Behavior scale represents more traditionally feminine behavior (i.e., housework, childcare, feminine paid labor), and less traditionally masculine behavior (i.e., hours spent in paid employment). For fathers, a high score on the Gendered Behavior scale represents less traditionally feminine behavior and more traditionally masculine behavior. A high score on the Sex Role Discrimination (Own Sex) measure indicates more knowledge about sex role stereotypes as they relate to members of the child's own sex, while a high score on the Sex Role Discrimination (Opposite Sex) measure indicates more knowledge about sex role stereotypes as they relate to members of the child's opposite sex. The Sex Role Preference (Adult Figures) subscale measure children's interest in sex-stereotyped careers. 
Table 7: Summary of hierarchical regressions predicting parents' early and concurrent gender ideology and children's gender-role attitudes.

\begin{tabular}{|c|c|c|c|c|c|c|c|c|c|c|c|c|c|c|c|c|c|c|}
\hline & \multicolumn{6}{|c|}{$\begin{array}{c}\text { Sex Role Discrimination } \\
\text { (Own Sex) }\end{array}$} & \multicolumn{6}{|c|}{$\begin{array}{c}\text { Sex Role Discrimination } \\
\text { (Opposite Sex) }\end{array}$} & \multicolumn{6}{|c|}{$\begin{array}{c}\text { Sex Role Preferences } \\
\text { (Adult Figures) }\end{array}$} \\
\hline & \multicolumn{3}{|c|}{ Model 1} & \multicolumn{3}{|c|}{ Model 2} & \multicolumn{3}{|c|}{ Model 1} & \multicolumn{3}{|c|}{ Model 2} & \multicolumn{3}{|c|}{ Model 1} & \multicolumn{3}{|c|}{ Model 2} \\
\hline & $B$ & SEB & $\beta$ & $B$ & SEB & $\beta$ & $B$ & $S E B$ & $\beta$ & $B$ & $S E B$ & $\beta$ & $B$ & SEB & $\beta$ & $B$ & $S E B$ & $\beta$ \\
\hline \multicolumn{19}{|l|}{ Mothers } \\
\hline Early GI & -1.31 & .89 & -.15 & -.55 & .96 & -.06 & -.70 & 1.34 & -.05 & -.61 & 1.47 & -.05 & .34 & 1.35 & .03 & .96 & 1.47 & .07 \\
\hline Concurrent GI & & & & -1.88 & .95 & $-.21^{+}$ & & & & -.22 & 1.46 & -.02 & & & & -1.54 & 1.43 & -.12 \\
\hline$R^{2}$ & & .02 & & & .06 & & & .00 & & & .00 & & & .001 & & & .01 & \\
\hline $\begin{array}{r}F \text { for change in } \\
R^{2}\end{array}$ & & 2.14 & & & $3.95^{+}$ & & & .27 & & & .02 & & & .06 & & & 1.16 & \\
\hline \multicolumn{19}{|l|}{ Fathers } \\
\hline Early GI & -1.19 & .98 & -.14 & -.91 & 1.27 & -.10 & -.36 & 1.37 & $-.28^{* *}$ & -3.59 & 1.77 & $-.28^{*}$ & 1.02 & 1.47 & .08 & 2.36 & .19 & .18 \\
\hline Concurrent GI & & & & -.46 & 1.26 & -.05 & & & & -.08 & 1.77 & -.01 & & & & -2.12 & 1.84 & -.17 \\
\hline$R^{2}$ & & .02 & & & .02 & & & .08 & & & .08 & & & .01 & & & .02 & \\
\hline $\begin{array}{r}F \text { for change in } \\
R^{2}\end{array}$ & & 1.47 & & & .13 & & & $7.09^{* *}$ & & & .00 & & & .48 & & & 1.33 & \\
\hline
\end{tabular}

Note. “GI” indicates parents’ gender ideology. ${ }^{+} p<.10 ;{ }^{*} p<.05 ;{ }^{* *} p<.01$. 
Table 8: Summary of hierarchical regressions predicting parents' early and concurrent gendered behaviors and children’s gender-role attitudes.

\begin{tabular}{|c|c|c|c|c|c|c|c|c|c|c|c|c|c|c|c|c|c|c|}
\hline & \multicolumn{6}{|c|}{$\begin{array}{c}\text { Sex Role Discrimination } \\
\text { (Own Sex) }\end{array}$} & \multicolumn{6}{|c|}{$\begin{array}{c}\text { Sex Role Discrimination } \\
\text { (Opposite Sex) }\end{array}$} & \multicolumn{6}{|c|}{$\begin{array}{l}\text { Sex Role Preferences } \\
\text { (Adult Figures) }\end{array}$} \\
\hline & \multicolumn{3}{|c|}{ Model 1} & \multicolumn{3}{|c|}{ Model 2} & \multicolumn{3}{|c|}{ Model 1} & \multicolumn{3}{|c|}{ Model 2} & \multicolumn{3}{|c|}{ Model 1} & \multicolumn{3}{|c|}{ Model 2} \\
\hline & $B$ & SEB & $\beta$ & $B$ & $S E B$ & $\beta$ & $B$ & SEB & $\beta$ & $B$ & $S E B$ & $\beta$ & $B$ & SEB & $\beta$ & $B$ & SEB & $\beta$ \\
\hline \multicolumn{19}{|l|}{ Mothers } \\
\hline Early Behavior & 1.96 & 1.15 & $.19^{+}$ & 2.04 & 1.26 & .21 & .39 & 1.78 & .03 & .27 & 1.93 & .02 & 5.21 & 1.62 & $.36^{* *}$ & 4.91 & 1.78 & $.34^{* *}$ \\
\hline $\begin{array}{r}\text { Concurrent } \\
\text { Behavior }\end{array}$ & & & & -.19 & 1.15 & -.02 & & & & .29 & 1.79 & .02 & & & & .71 & 1.65 & .05 \\
\hline$R^{2}$ & & .04 & & & .04 & & & .00 & & & .00 & & & .13 & & & .13 & \\
\hline $\begin{array}{r}F \text { for change in } \\
R^{2}\end{array}$ & & $2.89^{+}$ & & & .03 & & & .05 & & & .03 & & & $10.36^{* *}$ & & & .18 & \\
\hline \multicolumn{19}{|l|}{ Fathers } \\
\hline Early Behavior & 1.40 & 1.00 & .16 & .98 & 1.27 & .11 & .73 & 1.55 & .05 & -.51 & 1.99 & -.04 & 3.38 & 1.51 & $.25^{*}$ & 3.13 & 1.93 & .23 \\
\hline $\begin{array}{r}\text { Concurrent } \\
\text { Behavior }\end{array}$ & & & & .67 & 1.25 & .08 & & & & 1.97 & 1.99 & .15 & & & & .40 & 1.89 & .03 \\
\hline$R^{2}$ & & .03 & & & .03 & & & .00 & & & .02 & & & .06 & & & .06 & \\
\hline $\begin{array}{r}F \text { for change in } \\
R^{2}\end{array}$ & & 1.98 & & & .28 & & & .22 & & & .99 & & & $4.98^{*}$ & & & .05 & \\
\hline
\end{tabular}

Note. ${ }^{+} p<.10 ;{ }^{*} p<.05 ;{ }^{* *} p<.01$. 
Table 9: Summary of hierarchical regressions predicting parents' early and concurrent gender ideology and gendered behaviors and children’s genderrole attitudes.

\begin{tabular}{|c|c|c|c|c|c|c|c|c|c|c|c|c|c|c|c|c|c|c|}
\hline & \multicolumn{6}{|c|}{$\begin{array}{c}\text { Sex Role Discrimination } \\
\text { (Own Sex) }\end{array}$} & \multicolumn{6}{|c|}{$\begin{array}{c}\text { Sex Role Discrimination } \\
\text { (Opposite Sex) }\end{array}$} & \multicolumn{6}{|c|}{$\begin{array}{c}\text { Sex Role Preferences } \\
\text { (Adult Figures) }\end{array}$} \\
\hline & \multicolumn{3}{|c|}{ Model 1} & \multicolumn{3}{|c|}{ Model 2} & \multicolumn{3}{|c|}{ Model 1} & \multicolumn{3}{|c|}{ Model 2} & \multicolumn{3}{|c|}{ Model 1} & \multicolumn{3}{|c|}{ Model 2} \\
\hline & $B$ & SEB & $\beta$ & $B$ & $S E B$ & $\beta$ & $B$ & $S E B$ & $\beta$ & $B$ & $S E B$ & $\beta$ & $B$ & $S E B$ & $\beta$ & $B$ & SEB & $\beta$ \\
\hline \multicolumn{19}{|l|}{ Mothers } \\
\hline Early GI & -.83 & 1.30 & -.08 & -.46 & 1.33 & -.05 & -.86 & 2.06 & -.06 & -.86 & 2.14 & -.06 & -.95 & 2.05 & -.06 & .05 & 1.96 & .00 \\
\hline Concurrent GI & -2.32 & 1.35 & $-.23^{+}$ & -2.30 & 1.36 & $-.23^{+}$ & .63 & 2.16 & .04 & .69 & 2.20 & .04 & -.73 & 2.07 & -.05 & -.52 & 1.96 & -.27 \\
\hline Early Behavior & & & & 1.83 & 1.27 & .18 & & & & .15 & 2.03 & .01 & & & & 5.06 & 1.84 & $.35^{* *}$ \\
\hline $\begin{array}{r}\text { Concurrent } \\
\text { Behavior }\end{array}$ & & & & -.08 & 1.15 & -.01 & & & & .48 & 1.87 & .03 & & & & 1.06 & 1.69 & .08 \\
\hline$R^{2}$ & & .08 & & & .11 & & & .003 & & & .004 & & & .01 & & & .15 & \\
\hline $\begin{array}{r}F \text { for change in } \\
R^{2}\end{array}$ & & $2.87^{+}$ & & & 1.17 & & & .09 & & & .05 & & & .32 & & & $5.45^{* *}$ & \\
\hline \multicolumn{19}{|l|}{ Fathers } \\
\hline Early GI & -.49 & 1.28 & -.06 & -.27 & 1.29 & -.03 & -3.03 & 1.84 & -.24 & -3.12 & 1.88 & -.25 & 3.05 & 1.91 & .24 & 3.85 & 1.88 & .30 \\
\hline Concurrent GI & -.78 & 1.27 & -.09 & -.45 & 1.31 & -.05 & -.43 & 1.85 & -.03 & -.13 & 1.89 & -.01 & -2.49 & 1.88 & -.20 & -1.87 & 1.87 & -.15 \\
\hline Early Behavior & & & & .85 & 1.33 & .09 & & & & -1.65 & 1.90 & -.13 & & & & 3.76 & 1.92 & $.29^{+}$ \\
\hline $\begin{array}{l}\text { Concurrent } \\
\text { Behavior }\end{array}$ & & & & .76 & 1.14 & .09 & & & & 2.16 & 1.94 & .17 & & & & .27 & 1.19 & .02 \\
\hline$R^{2}$ & & .02 & & & .04 & & & .07 & & & .09 & & & .04 & & & .12 & \\
\hline $\begin{array}{r}F \text { for change in } \\
R^{2}\end{array}$ & & .67 & & & .86 & & & $2.66^{+}$ & & & .66 & & & 1.37 & & & $3.07^{+}$ & \\
\hline
\end{tabular}

Note. "GI" indicates parental gender ideology. ${ }^{+} p<.10 ;{ }^{*} p<.05 ;{ }^{* *} p<.01$. 
Table 10: Summary of hierarchical regressions predicting mothers' early and concurrent gender ideology and gendered behaviors and children’s gender-role attitudes.

\begin{tabular}{ccccccccc}
\multicolumn{8}{c}{$\begin{array}{c}\text { Sex Role Discrimination } \\
\text { (Own Sex) }\end{array}$} \\
\hline & Model 1 & & \multicolumn{3}{c}{ Model 2 } & & \\
\hline B & SE B & $\beta$ & $B$ & SE B & $\beta$ & $B$ & SE B & $\beta$
\end{tabular}

Mothers

$\begin{array}{rccccccccc}\text { Early GI } & -.46 & 1.33 & -.05 & -.45 & 1.34 & -.05 & -1.95 & 1.92 & -.19 \\ \text { Concurrent GI } & -2.30 & 1.36 & -.23^{+} & -2.32 & 1.38 & -.23^{+} & -1.75 & 1.90 & -.17 \\ \text { Early Behavior } & 1.83 & 1.27 & .18 & 1.79 & 1.29 & .18 & -.72 & 1.69 & -.07 \\ \text { Concurrent Behavior } & -.08 & 1.15 & -.01 & -.01 & 1.23 & -.001 & -3.73 & 1.63 & -.41^{*} \\ & & & & & & & & & \\ \text { Child Sex } & & & & -.35 & 2.21 & -.02 & 1.16 & 2.14 & .07\end{array}$

Early GI x Child Sex

1.09

$\begin{array}{lll}2.52 & .08 & .43\end{array}$

Concurrent GI x Child Sex

$\begin{array}{lll}-.63 & 2.54 & -.04\end{array}$

Early Behavior $x$ Child Sex

$3.92 \quad 2.38 \quad .29$

Concurrent Behavior x Child Sex

$6.58 \quad 2.27 \quad .51^{* *}$

$\begin{array}{rccc}R^{2} & .11 & .11 & .30 \\ F \text { for change in } R^{2} & 2.03 & .03 & 4.37^{* *}\end{array}$

Note. "GI" indicates parental gender ideology. ${ }^{+} p<.10 ;{ }^{*} p<.05 ;{ }^{* *} p<.01$. 
Table 11: Summary of trimmed exploratory hierarchical regressions predicting children's sex role discrimination (own sex).

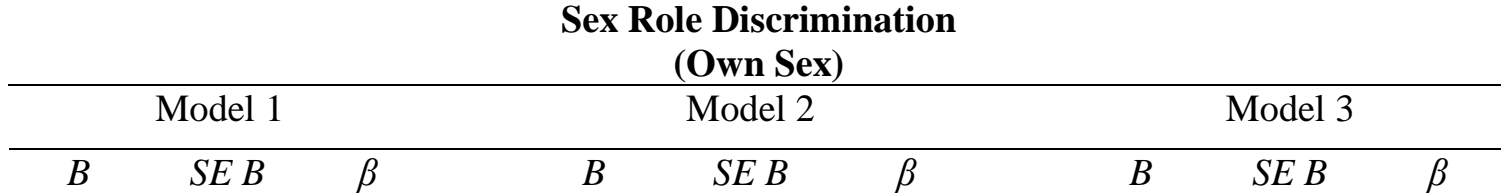

\begin{tabular}{|c|c|c|c|c|c|c|c|c|c|}
\hline Mothers’ Early GI & -.74 & 1.71 & -.07 & -1.33 & 1.61 & -.13 & -1.78 & 1.27 & -.18 \\
\hline Mothers’ Early Behavior & -1.52 & 2.18 & -.15 & 1.97 & 1.67 & .19 & -.34 & 1.73 & -.03 \\
\hline Mothers Concurrent GI & -2.25 & 1.60 & -.21 & -1.60 & 1.50 & -.15 & -1.86 & 1.24 & -.19 \\
\hline Mothers’ Concurrent Behavior & .12 & 1.56 & .01 & -6.30 & 2.23 & $-.64^{* *}$ & -3.77 & 1.55 & $-.41^{*}$ \\
\hline Fathers’ Early GI & .18 & 1.53 & .01 & 1.11 & 1.44 & .11 & - & - & - \\
\hline Fathers’ Early Behavior & -.95 & 1.84 & -.09 & -.84 & 1.71 & -.09 & -.67 & 1.24 & -.07 \\
\hline Fathers’ Concurrent GI & -.29 & 1.90 & -.02 & -2.45 & 1.82 & -.20 & - & - & - \\
\hline Fathers’ Concurrent Behavior & .58 & 1.58 & .06 & .53 & 1.47 & .06 & - & - & - \\
\hline Child Sex & 1.68 & 2.81 & .09 & .75 & 2.56 & .04 & .86 & 2.05 & .05 \\
\hline rs’ Early Behavior x Child Sex & 7.12 & 2.58 & $.53^{* *}$ & - & - & - & 4.06 & 2.24 & $.30^{+}$ \\
\hline urrent Behavior x Child Sex & - & - & - & 11.04 & 2.73 & $.86^{* * *}$ & 7.50 & 2.26 & $.57^{* *}$ \\
\hline
\end{tabular}
$R^{2}$
.23
.34
.35

$F$ for change in $R^{2}$

$7.59^{* *}$

$16.29^{* * *}$

$10.82^{* * *}$

Note. "GI” indicates parental gender ideology. ${ }^{+} p<.10 ;{ }^{*} p<.05 ;{ }^{* *} p<.01 ;{ }^{* * *} p<.001$. 
Table 12: Summary of trimmed exploratory hierarchical regressions predicting children's sex role discrimination (opposite sex).

\begin{tabular}{cccccc}
\multicolumn{5}{c}{$\begin{array}{c}\text { Sex Role Discrimination } \\
\text { (Opposite Sex) }\end{array}$} \\
\hline & Model 1 & & Model 2 & \\
\hline$B$ & $S E B$ & $\beta$ & $B$ & $S E$ B & $\beta$
\end{tabular}

\begin{tabular}{|c|c|c|c|c|c|c|}
\hline Mothers’ Early GI & -1.64 & 2.60 & -.11 & - & - & \\
\hline Mothers’ Early Behavior & .11 & 2.80 & .01 & - & - & \\
\hline Mothers' Concurrent GI & 1.91 & 2.51 & .08 & - & - & \\
\hline Mothers' Concurrent Behavior & .49 & 2.39 & .03 & - & - & \\
\hline Fathers' Early GI & -8.72 & 3.72 & $-.58^{*}$ & -6.95 & 2.09 & -.54 \\
\hline Fathers’ Early Behavior & -.21 & 2.85 & -.15 & -1.26 & 1.94 & -.09 \\
\hline Fathers' Concurrent GI & .39 & 2.97 & .02 & - & - & - \\
\hline Fathers’ Concurrent Behavior & 2.71 & 2.46 & .19 & 1.18 & 1.93 & .09 \\
\hline Child Sex & -1.96 & 4.22 & -.07 & 1.17 & 3.02 & .04 \\
\hline Fathers’ Early GI x Child Sex & 7.82 & 4.20 & $.43^{+}$ & 5.95 & 2.83 & $.33^{*}$ \\
\hline$R^{2}$ & & .15 & & & .15 & \\
\hline$F$ for change in $R^{2}$ & & $3.46^{+}$ & & & $4.45^{*}$ & \\
\hline
\end{tabular}

Note. "GI" indicates parental gender ideology. ${ }^{+} p<.10 ;{ }^{*} p<.05 ;{ }^{* *} p<.01$. 
Table 13: Summary of exploratory hierarchical regressions predicting children's sex role preferences (adult figures).

\begin{tabular}{ccc} 
& $\begin{array}{c}\text { Sex Role Preferences } \\
\text { (Adult Figures) }\end{array}$ & \\
\hline & Model 1 & $\beta$
\end{tabular}

$\begin{array}{rrcc}\text { Mothers' Early GI } & -1.43 & 2.38 & -.09 \\ \text { Mothers' Early Behavior } & 5.87 & 2.51 & .41^{*} \\ \text { Mothers' Concurrent GI } & -1.68 & 2.24 & -.11 \\ \text { Mothers' Concurrent Behavior } & -.10 & 2.06 & -.01 \\ \text { Fathers' Early GI } & 5.68 & 2.12 & .39^{*} \\ \text { Fathers' Early Behavior } & .87 & 2.61 & .06 \\ \text { Fathers' Concurrent GI } & -3.68 & 2.57 & -.21 \\ \text { Fathers' Concurrent Behavior } & -.65 & 2.18 & -.05\end{array}$

\begin{tabular}{cc}
$R^{2}$ & .27 \\
$F$ & $2.28^{*}$ \\
\hline Note. "GI" indicates parental gender ideology. ${ }^{+} p<.10 ;{ }^{*} p<.05 ;{ }^{* *} p<.01 ;{ }^{* * *} p<.001$.
\end{tabular}




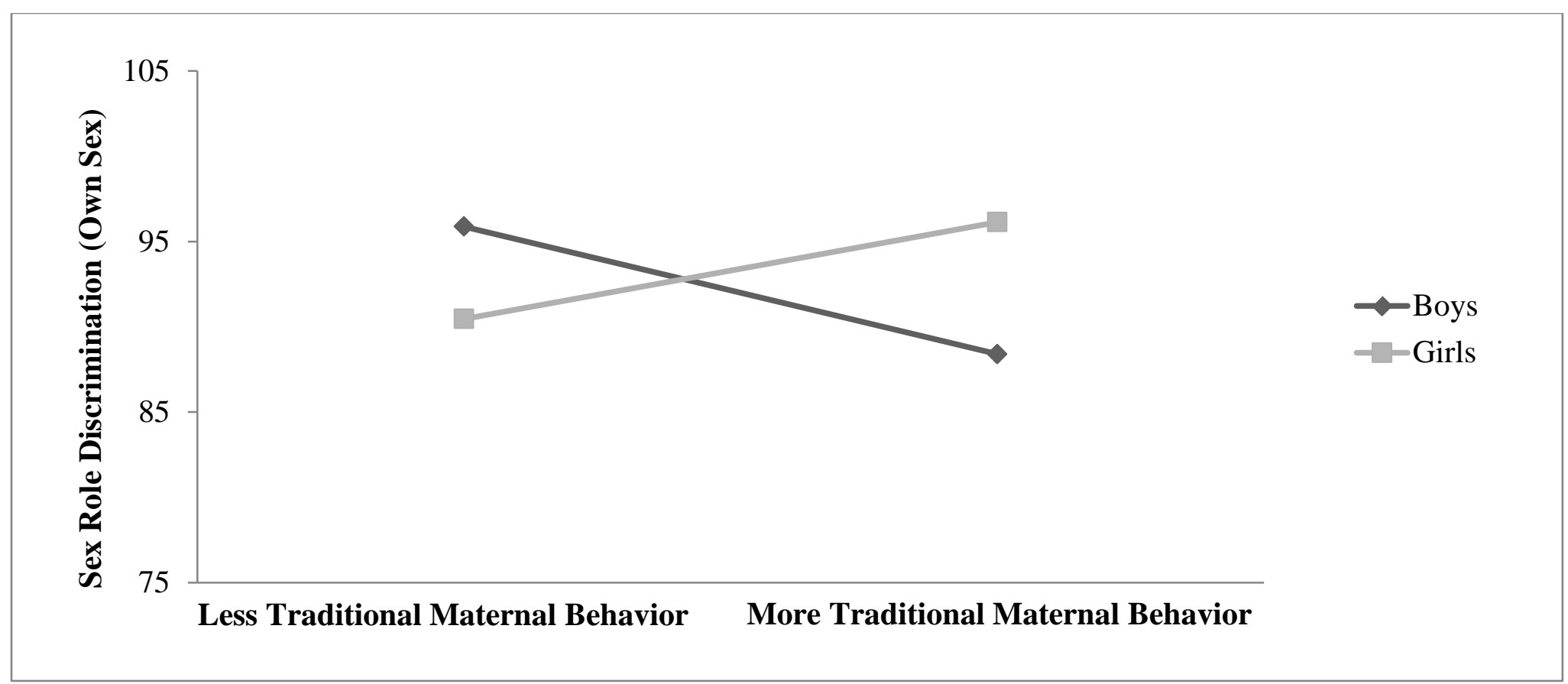

Figure 1: Interaction between mothers' gendered behavior during year six and child sex as it predicts sex role discrimination (own sex).

A high score on the Gendered Behavior scale represents more traditionally feminine behavior (i.e., housework, childcare, feminine paid labor), and less traditionally masculine behavior (i.e., hours spent in paid employment). For children, a high score on the Sex Role Discrimination (Own Sex) measure indicates more knowledge about sex role stereotypes as they relate to members of the child's own sex. 


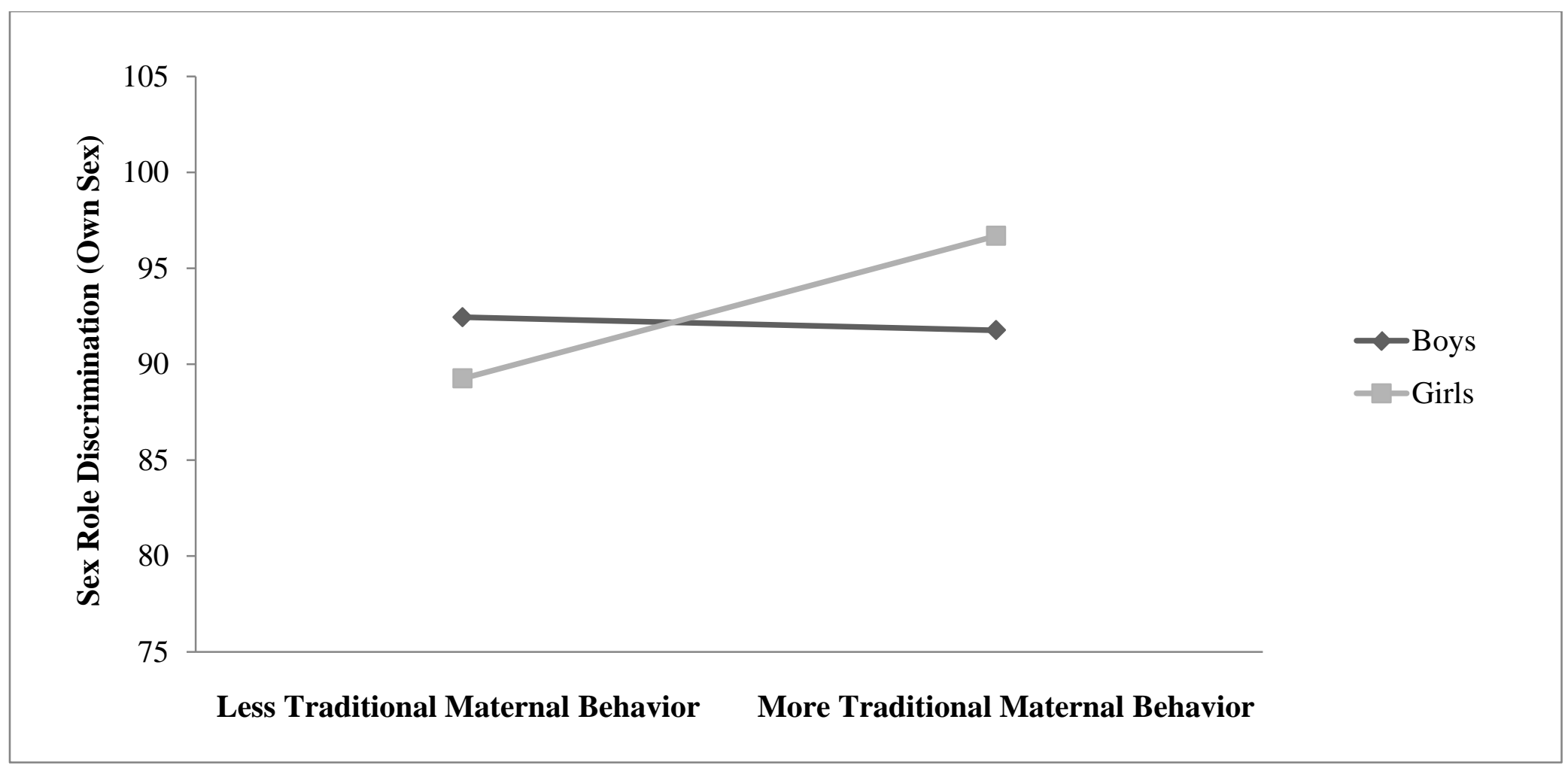

Figure 2: Interaction between mothers’ gendered behavior during year one and child sex as it predicts sex role discrimination (own sex) in an exploratory model using hierarchical regression.

A high score on the Gendered Behavior scale represents more traditionally feminine behavior (i.e., housework, childcare, feminine paid labor), and less traditionally masculine behavior (i.e., hours spent in paid employment). For children, a high score on the Sex Role Discrimination (Own Sex) measure indicates more knowledge about sex role stereotypes as they relate to members of the child's own sex. 


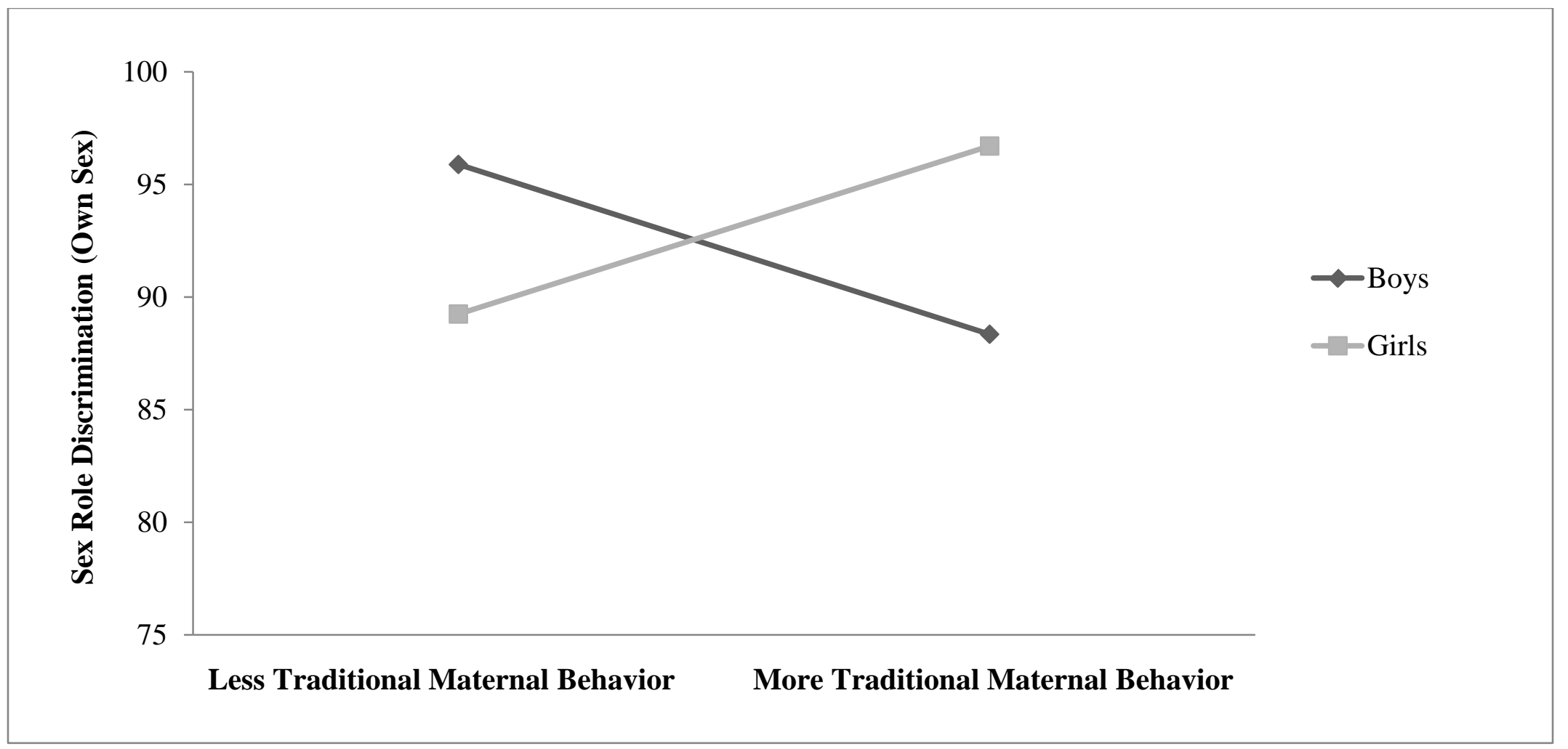

Figure 3: Interaction between mothers' concurrent gendered behavior and child sex as it predicts sex role discrimination (own sex) in an exploratory model using hierarchical regression.

A high score on the Gendered Behavior scale represents more traditionally feminine behavior (i.e., housework, childcare, feminine paid labor), and less traditionally masculine behavior (i.e., hours spent in paid employment). For children, a high score on the Sex Role Discrimination (Own Sex) measure indicates more knowledge about sex role stereotypes as they relate to members of the child's own sex 


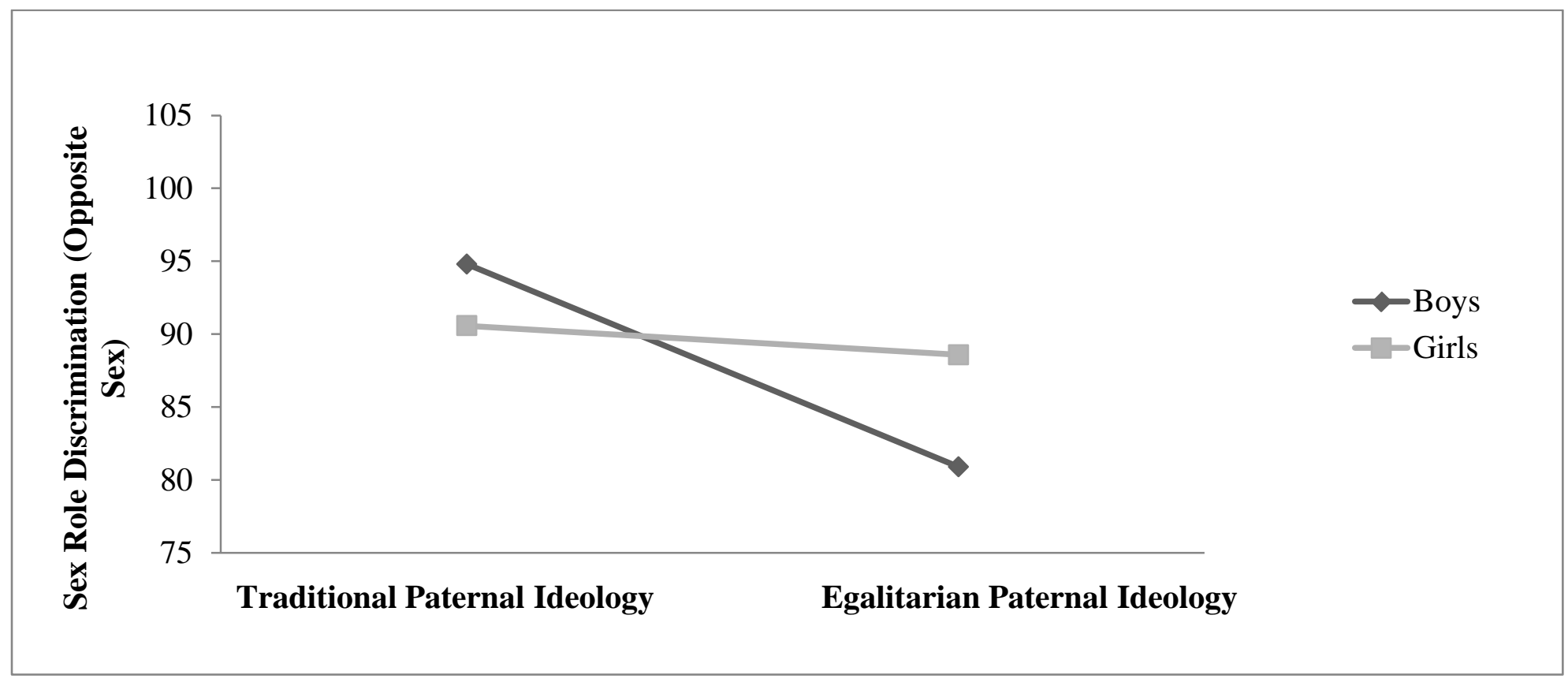

Figure 4: Interaction between fathers' ideology during year one and child sex as it predicts sex role discrimination (opposite sex) in an exploratory model using hierarchical regression.

A high score on the Gendered Behavior scale represents more traditionally feminine behavior (i.e., housework, childcare, feminine paid labor), and less traditionally masculine behavior (i.e., hours spent in paid employment). For children, a high score on the Sex Role Discrimination (Opposite Sex) measure indicates more knowledge about sex role stereotypes as they relate to members of the child's opposite sex. 


\section{APPENDIX A}

\section{MEN'S AND WOMEN'S ROLES}

(Brogran \& Kutner, 1976)

The statements listed below describe attitudes which different people have toward the roles of men and women. There are no right or wrong answers, only opinions. Express your personal opinion about each statement (not the feelings that you think people in general may have) by circling the number that indicates your agreement.

\begin{tabular}{|c|c|c|c|c|c|}
\hline 1 & 2 & 3 & 4 & 5 & 6 \\
\hline $\begin{array}{c}\text { Strongly } \\
\text { agree }\end{array}$ & $\begin{array}{c}\text { Moderately } \\
\text { agree }\end{array}$ & $\begin{array}{c}\text { Agree } \\
\text { slightly } \\
\text { more than } \\
\text { disagree }\end{array}$ & $\begin{array}{c}\text { Disagree } \\
\text { slightly } \\
\text { more than } \\
\text { agree }\end{array}$ & $\begin{array}{c}\text { Moderately } \\
\text { disagree }\end{array}$ & $\begin{array}{c}\text { Strongly } \\
\text { disagree }\end{array}$ \\
\hline
\end{tabular}

1. It is more important for a wife to help her husband's career than $\begin{array}{llllll}1 & 2 & 3 & 4 & 5 & 6\end{array}$ to have a career herself.

2. The idea of young girls participating in Little League baseball $\quad \begin{array}{llllll}1 & 2 & 3 & 4 & 5\end{array}$ competition is ridiculous.

3. The amount of time and energy devoted to a career, home and $\quad \begin{array}{llllll}1 & 2 & 3 & 4 & 5 & 6\end{array}$ family should be determined by one's personal desires and interests rather than by one's sex.

4. It is more important for a woman to keep her figure and dress $\quad \begin{array}{llllll}1 & 2 & 3 & 4 & 5 & 6\end{array}$ fashionably than it is for a man.

5. The old saying that "a woman's place is in the home” is still $\quad \begin{array}{llllll}1 & 2 & 3 & 4 & 5\end{array}$ basically true and should remain true.

6. A woman should not be too competitive with men and should $\quad \begin{array}{llllll}1 & 2 & 3 & 4 & 5\end{array}$ keep her peace rather than show a man he is wrong.

7. A woman whose job involves contact with the public, e.g., $\quad \begin{array}{llllll}1 & 2 & 3 & 4 & 5 & 6\end{array}$ salesperson or teacher, should not continue to work when she is noticeably pregnant.

8. The husband should take primary responsibility for major family decisions, such as the purchase of a home or car.

9. In groups that have both male and female members, the top $\quad \begin{array}{llllll}1 & 2 & 3 & 4 & 5\end{array}$ leadership positions should be held by males.

10. Married women who have school-aged children should not work outside the home unless it is economically necessary. 


\begin{tabular}{|c|c|c|c|c|c|}
\hline 1 & 2 & 3 & 4 & 5 & 6 \\
\hline $\begin{array}{c}\text { Strongly } \\
\text { agree }\end{array}$ & $\begin{array}{c}\text { Moderately } \\
\text { agree }\end{array}$ & $\begin{array}{c}\text { Agree } \\
\text { slightly more } \\
\text { than disagree }\end{array}$ & $\begin{array}{c}\text { Disagree } \\
\text { slightly } \\
\text { more than } \\
\text { agree }\end{array}$ & $\begin{array}{c}\text { Moderately } \\
\text { disagree }\end{array}$ & $\begin{array}{c}\text { Strongly } \\
\text { disagree }\end{array}$ \\
\hline
\end{tabular}

11. If a man and a woman are being considered for the same job

$\begin{array}{llllll}1 & 2 & 3 & 4 & 5 & 6\end{array}$ and the woman is slightly better qualified, the job should still go to the man because he is more likely to have a family to support.

12. Marriage is a partnership in which the wife and husband should $\quad \begin{array}{llllll}1 & 2 & 3 & 4 & 5 & 6\end{array}$ share the economic responsibility of supporting the family.

13. A woman should not accept a career promotion if it would require her family to move and her husband to find another job.

14. A married woman who chooses not to have children because $\quad \begin{array}{llllll}1 & 2 & 3 & 4 & 5 & 6\end{array}$ she prefers to pursue her career should not feel guilty.

15. Married women who have preschool-aged children should not $\quad \begin{array}{lllllll}1 & 2 & 3 & 4 & 5 & 6\end{array}$ work outside the home unless it is economically necessary.

16. It is generally better to have a man at the head of a department $\quad \begin{array}{llllll}1 & 2 & 3 & 4 & 5 & 6\end{array}$ composed of both men and women employees.

17. A husband should feel uncomfortable if his wife earns a larger $\quad \begin{array}{lllllll}1 & 2 & 3 & 4 & 5 & 6\end{array}$ salary than he does.

18. It is alright for women to hold local political offices. $\quad \begin{array}{llllll}1 & 2 & 3 & 4 & 5 & 6\end{array}$

19. A male student and a female student are equally qualified for a $\begin{array}{lllllll}1 & 2 & 3 & 4 & 5 & 6\end{array}$ certain scholarship; it should be awarded to the male student on the grounds that he has greater "career potential."

20. The use of profane or obscene language by a woman is more $\quad \begin{array}{lllllll}1 & 2 & 3 & 4 & 5 & 6\end{array}$ objectionable than the same usage by a man.

21. It is acceptable for boys, as well as girls, to play with dolls. $\quad \begin{array}{llllll}1 & 2 & 3 & 4 & 5 & 6\end{array}$

22. Girls should primarily be encouraged to enter "feminine" $\quad \begin{array}{llllll}1 & 2 & 3 & 4 & 5\end{array} 6$ careers such as nursing, public school teaching, library science, etc.

23. Women should feel free to compete in any form of athletics. $\quad \begin{array}{llllll}1 & 2 & 3 & 4 & 5 & 6\end{array}$

24. Parents should encourage just as much independence in their $\quad \begin{array}{lllllll}1 & 2 & 3 & 4 & 5 & 6\end{array}$ daughters as in their sons. 
25. Women should be able to compete with men for jobs that have $\quad \begin{array}{llllll}1 & 2 & 3 & 4 & 5 & 6\end{array}$ traditionally belonged to men, such as telephone lineman.

26. It is O.K. for a wife to keep her own last name, rather than take $\quad \begin{array}{llllll}1 & 2 & 3 & 4 & 5 & 6\end{array}$ her husband's name.

27. A woman should not be president of the United States.

$\begin{array}{llllll}1 & 2 & 3 & 4 & 5 & 6\end{array}$

28. Career education for boys should have higher priority with parents and teachers than career education for girls.

29. Even though a wife works outside the home, the husband should be the main breadwinner and the wife should have the responsibility for running the household.

30. In elementary school, girls should wear dresses rather than pants or jeans to school.

31. It is acceptable for a woman to be a member of the church clergy.

32. It is acceptable for women to hold important elected political offices in state and national government.

33. It is not a good idea for a husband to stay home and care for the $\quad \begin{array}{llllllll}1 & 2 & 3 & 4 & 5 & 6\end{array}$ children while his wife is employed full-time outside the home.

34. The only reason girls need career education is that they may not $\quad \begin{array}{lllllll}1 & 2 & 3 & 4 & 5 & 6\end{array}$ marry or remain married.

35. A man should always offer his seat to a woman who is standing $\begin{array}{llllll}1 & 2 & 3 & 4 & 5 & 6\end{array}$ on a crowded bus.

36. Men should be able to compete with women for jobs that have $\quad \begin{array}{llllll}1 & 2 & 3 & 4 & 5 & 6\end{array}$ traditionally belonged to women, such as telephone operator.

37. It's important to raise a son so he will be able to hold down a good job when he's grown, but that's not as important with a daughter.

38. It's okay for children to help around the house, but I would not $\begin{array}{llllll}1 & 2 & 3 & 4 & 5 & 6\end{array}$ ask a son to dust or set the table.

39. Education is important for both sons and daughters but is more $\begin{array}{llllll}1 & 2 & 3 & 4 & 5 & 6\end{array}$ important for a son. 


\section{APPENDIX B}

\section{ATTITUDES TOWARDS WOMEN SCALE}

(Spence \& Helmreich, 1972; 1978)

The statements listed below describe attitudes toward the roles of women in society which different people have. There are no right or wrong answers, only opinions. You are asked to express your feeling about each statement by indicating whether you (1) agree strongly, (2) agree mildly, (3) disagree, or (4) disagree strongly.

\begin{tabular}{|c|c|c|c|}
\hline 1 & 2 & 3 & 4 \\
\hline Agree strongly & Agree mildly & Disagree mildly & Disagree strongly \\
& & & \\
\hline
\end{tabular}

1. Swearing and obscenity are more repulsive in the speech of a $\quad \begin{array}{llll}1 & 2 & 3 & 4\end{array}$ woman than a man.

2. Under modern economic conditions with women being active $\quad \begin{array}{llll}1 & 2 & 3 & 4\end{array}$ outside the home, men should share in household tasks such as washing dishes and doing laundry.

3. It is insulting to women to have the "obey" clause remain in the $\begin{array}{llll}1 & 2 & 3 & 4\end{array}$ marriage service.

4. A woman should be as free as a man to propose marriage. $\quad \begin{array}{llll}1 & 2 & 3 & 4\end{array}$

5. Women should worry less about their rights and more about $\quad \begin{array}{llll}1 & 2 & 3 & 4\end{array}$ becoming good wives and mothers.

6. $\quad$ Women should assume their rightful place in business and all $\quad \begin{array}{llll}1 & 2 & 3 & 4\end{array}$ the professions along with men.

7. A woman should not expect to go to exactly the same places or $\begin{array}{llll}1 & 2 & 3 & 4\end{array}$ to have quite the same freedom of action as a man.

8. It is ridiculous for a woman to operate large machinery and for $\begin{array}{llll}1 & 2 & 3 & 4\end{array}$ a man to sew on a button.

9. The intellectual leadership of a community should be largely in $\begin{array}{llll}1 & 2 & 3 & 4\end{array}$ the hands of men.

10. Women should be given equal opportunity with men for $\quad \begin{array}{llll}1 & 2 & 3 & 4\end{array}$ apprenticeship in the various trades. 
11. Women earning as much as their dates should bear equally the

$\begin{array}{llll}1 & 2 & 3 & 4\end{array}$ expense when they go out together.

12. Sons in a family should be given more encouragement to go to $\begin{array}{llll}1 & 2 & 3 & 4\end{array}$ college than daughters.

13. In general, the father should have greater authority than the

$\begin{array}{llll}1 & 2 & 3 & 4\end{array}$ mother in the bringing up of children.

14. Economic and social freedom is worth a lot more to women

$\begin{array}{llll}1 & 2 & 3 & 4\end{array}$ than acceptance of the ideal of femininity which has been set up by men.

15. There are many jobs in which men should be given preference $\quad \begin{array}{llll}1 & 2 & 3 & 4\end{array}$ over women in being hired or promoted. 


\section{APPENDIX C \\ QUESTIONS ABOUT WIVES’ AND HUSBANDS’ WORK PREFERENCES AND EMPLOYMENT}

While some individuals have a strong desire to work outside of the home, others would rather not. How do you feel about working now? Do you (read responses):

strongly prefer to work prefer to work

prefer not to work

strongly prefer not to work

For some men, whether or not their wife/partner works outside of the home makes little difference to them while others have strong feelings one way or the other. How do you feel about [wife/partner] working now? Do you (read responses):

strongly prefer that she work prefer that she work prefer that she not work strongly prefer that she not work

Sum the hours per week for all jobs. Confirm this number with interviewee.

total work hours 


\section{APPENDIX D \\ WHO DOES WHAT? \\ (Cowan \& Cowan; Barnett \& Baruch, 1987)}

1. How do you feel about the fairness of your relationship when it comes to the division of household tasks? Is it:

Very unfair to you

Slightly unfair to you

Fair to both you and your spouse/partner

Slightly unfair to your partner

Very unfair to your partner

Please circle the number which represents the percentage of YOUR OWN contribution to each of the following household tasks. If an item is Not Applicable, please write "NA" in the margin. For example, item 7 is not applicable if you don't own a pet.

\begin{tabular}{|c|c|c|c|c|}
\hline$\underline{1}$ & $\underline{2}$ & $\underline{3}$ & $\underline{4}$ & $\underline{5}$ \\
\hline $0-20 \%$ & $20-40 \%$ & $40-60 \%$ & $60-80 \%$ & $80-100 \%$ \\
$\begin{array}{c}\text { Mostly or always } \\
\text { my spouse/partner }\end{array}$ & $\begin{array}{c}\text { More likely my } \\
\text { spouse/partner }\end{array}$ & $\begin{array}{c}\text { Shared about } \\
\text { equally }\end{array}$ & More likely me & $\begin{array}{c}\text { Mostly or always } \\
\text { me }\end{array}$ \\
\hline
\end{tabular}

\begin{tabular}{|c|c|c|c|c|c|}
\hline 1. & Make beds or change bed linens & 12 & 3 & 4 & 5 \\
\hline 2. & Cleaning (vacuum, clean bathrooms, sweep floors) & 12 & 3 & 4 & 5 \\
\hline 3. & Food preparation (cook, set table, prepare meal or snack) & 12 & 3 & 4 & 5 \\
\hline 4. & Dish-washing & 12 & 3 & 4 & 5 \\
\hline 5. & Take out garbage, recycling & 12 & 3 & 4 & 5 \\
\hline 6. & Outdoor work (yard work, rake, mow, shovel snow, garden) & 12 & 3 & 4 & 5 \\
\hline 7. & Care for pet (feed, walk, put out) & 12 & 3 & 4 & 5 \\
\hline 8. & Laundry (wash, iron, fold clothes) & 12 & 3 & 4 & 5 \\
\hline 9. & Run errands outside of home including grocery shopping & 12 & 3 & 4 & 5 \\
\hline 10. & Upkeep of car including repairs, washing and vacuuming & 12 & 3 & 4 & 5 \\
\hline & Small repairs around the house & 12 & 3 & 4 & 5 \\
\hline 12. & Taking care of financial matters (write-out bills, figure out budget) & 12 & 3 & 4 & 5 \\
\hline 13. & Prepare for events and activities, like birthdays or anniversaries & 12 & 3 & 4 & 5 \\
\hline 14. & $\begin{array}{l}\text { Buys presents, and/or makes calls to acknowledge important events } \\
\text { for family, friends or co-workers }\end{array}$ & 12 & 3 & 4 & 5 \\
\hline \multicolumn{6}{|c|}{ 15. How satisfied are you with the current division of household tasks? } \\
\hline \multicolumn{6}{|c|}{$\begin{array}{r}\text { Very dissatisfied } \\
\text { mewhat dissatisfied } \\
\text { fied nor dissatisfied } \\
\text { Somewhat satisfied } \\
\text { Very satisfied }\end{array}$} \\
\hline
\end{tabular}




\section{APPENDIX E \\ CHILD CARE RESPONSIBILITY}

\section{PART I: Please check the response which best describes your present feelings.}

1. How do you feel about the fairness of your relationship when it comes to the division of child care tasks? Is it: (read responses)

$$
\begin{array}{r}
\text { Very unfair to you } \\
\text { Slightly unfair to you } \\
\text { Fair to both you and your spouse/partner } \\
\text { Slightly unfair to your partner } \\
\text { Very unfair to your spouse/partner }
\end{array}
$$

PART II: The following is a list of specific child care tasks. Using the scale provided, please circle the number which represents the percentage of YOUR OWN contribution to each one.

\begin{tabular}{|c|c|c|c|c|}
\hline$\underline{1}$ & $\underline{2}$ & $\underline{3}$ & $\underline{4}$ & $\underline{5}$ \\
\hline $0-20 \%$ & $20-40 \%$ & $40-60 \%$ & $60-80 \%$ & $80-100 \%$ \\
$\begin{array}{c}\text { Mostly or } \\
\text { always my } \\
\text { spouse }\end{array}$ & $\begin{array}{c}\text { More likely my } \\
\text { spouse }\end{array}$ & $\begin{array}{c}\text { Shared about } \\
\text { equally }\end{array}$ & More likely me & $\begin{array}{c}\text { Mostly or always } \\
\text { me }\end{array}$ \\
\hline
\end{tabular}

1. $\quad$ Feeding the baby

2. Changing the baby's diaper

3. Soothing the baby

4. Getting up at night with the baby

5. Putting the baby to sleep

6. Giving the baby a bath

7. Helping the baby learn new skills

8. $\quad$ Dressing the baby

9. Planning the baby's activities

10. Picking up after the baby

11. Playing with the baby

12. Reading/singing to the baby

13. Taking the baby on an outing

14. Taking the baby to a doctor's appointment

15. Taking care of the baby when he or she is sick

$\begin{array}{lllll}1 & 2 & 3 & 4 & 5 \\ 1 & 2 & 3 & 4 & 5 \\ 1 & 2 & 3 & 4 & 5 \\ 1 & 2 & 3 & 4 & 5 \\ 1 & 2 & 3 & 4 & 5 \\ 1 & 2 & 3 & 4 & 5 \\ 1 & 2 & 3 & 4 & 5 \\ 1 & 2 & 3 & 4 & 5 \\ 1 & 2 & 3 & 4 & 5 \\ 1 & 2 & 3 & 4 & 5 \\ 1 & 2 & 3 & 4 & 5 \\ 1 & 2 & 3 & 4 & 5 \\ 1 & 2 & 3 & 4 & 5 \\ 1 & 2 & 3 & 4 & 5 \\ 1 & 2 & 3 & 4 & 5\end{array}$




\section{PART III: Please check the response which best describes your present feelings}

1. How satisfied are you with the current division of child care tasks?

$$
\begin{array}{r}
\text { Very dissatisfied } \\
\text { Somewhat dissatisfied } \\
\text { Neither satisfied nor dissatisfied } \\
\text { Somewhat satisfied } \\
\text { Very satisfied }
\end{array}
$$




\section{APPENDIX F}

\section{CHILDCARE INVOLVEMENT}

(Bouchard \& Lee, 2000)

\section{Daily Activities}

Please indicate how often you and your partner engage in the following activities with your child.

\begin{tabular}{|c|c|c|c|c|c|c|}
\hline 1 & 2 & 3 & 4 & 5 & 6 & 7 \\
\hline Never & $\begin{array}{c}\text { Very rarely } \\
\text { (Once a } \\
\text { week) }\end{array}$ & $\begin{array}{c}\text { Rarely } \\
\text { (Twice a } \\
\text { week) }\end{array}$ & $\begin{array}{c}\text { Sometimes } \\
\text { (3-4 times a } \\
\text { week) }\end{array}$ & $\begin{array}{c}\text { Often } \\
\text { (5 times a } \\
\text { week) }\end{array}$ & $\begin{array}{c}\text { Very often } \\
\text { (6 times a } \\
\text { week) }\end{array}$ & $\begin{array}{c}\text { Almost always } \\
\text { (7 times a } \\
\text { week) }\end{array}$ \\
\hline
\end{tabular}

\section{Example 1:}

If you and your partner both put your child to bed every evening you would mark:

$\begin{array}{lllllllll}\text { You } & 1 & 2 & 3 & 4 & 5 & 6 & 7 \\ \text { Your partner } & 1 & 2 & 3 & 4 & 5 & 6 & 7\end{array}$

\section{Example 2:}

If you put your child to bed two nights a week and your partner puts your child to bed the other nights, you would mark:

$\begin{array}{llllllll}\text { You } & 1 & 2 & 3 & 4 & 5 & 6 & 7 \\ \text { Your partner } & 1 & 2 & 3 & 4 & 5 & 6 & 7\end{array}$

\begin{tabular}{|c|c|c|c|c|c|c|c|}
\hline \multicolumn{8}{|c|}{ 1. Put your child to bed in the evening } \\
\hline You & 1 & 2 & 3 & 4 & 5 & 6 & 7 \\
\hline Your partner & 1 & 2 & 3 & 4 & 5 & 6 & 7 \\
\hline \multicolumn{8}{|c|}{ 2. Help your child with the morning routine (get dressed, have breakfast) } \\
\hline You & 1 & 2 & 3 & 4 & 5 & 6 & 7 \\
\hline Your partner & 1 & 2 & 3 & 4 & 5 & 6 & 7 \\
\hline \multicolumn{8}{|c|}{ 3. Pick clothes your child will wear that day } \\
\hline You & 1 & 2 & 3 & 4 & 5 & 6 & 7 \\
\hline Your partner & 1 & 2 & 3 & 4 & 5 & 6 & 7 \\
\hline \multicolumn{8}{|c|}{ 4. Help your child with any personal problems } \\
\hline You & 1 & 2 & 3 & 4 & 5 & 6 & 7 \\
\hline Your partner & 1 & 2 & 3 & 4 & 5 & 6 & 7 \\
\hline \multicolumn{8}{|c|}{ 5. Read a book or tell a story to your child } \\
\hline You & 1 & 2 & 3 & 4 & 5 & 6 & 7 \\
\hline Your partner & 1 & 2 & 3 & 4 & 5 & 6 & 7 \\
\hline
\end{tabular}




\begin{tabular}{|llllllll|} 
You & 1 & 2 & 3 & 4 & 5 & 6 & 7 \\
Your partner & 1 & 2 & 3 & 4 & 5 & 6 & 7 \\
\hline 7. Play a game with your child \\
\hline You & 1 & 2 & 3 & 4 & 5 & 6 & 7 \\
Your partner & 1 & 2 & 3 & 4 & 5 & 6 & 7 \\
\hline
\end{tabular}

\section{Occasional Activities}

For the following activities which do not take place every day, please use the following scale:

\begin{tabular}{|c|c|c|c|c|c|c|}
\hline 1 & 2 & 3 & 4 & 5 & 6 & 7 \\
\hline Never & $\begin{array}{c}\text { Very } \\
\text { rarely }\end{array}$ & Sometimes & $\begin{array}{c}\text { Half the } \\
\text { time }\end{array}$ & Often & Very often & Every time \\
\hline
\end{tabular}

\section{Example 1.}

If you are the person who usually disciplines your child when the need arises and your partner sometimes disciplines your child you would mark:

\begin{tabular}{|c|c|c|c|c|c|}
\hline You & 1 & 2 & 4 & 5 & 6 \\
\hline Your partner & 1 & 2 & 4 & 5 & 6 \\
\hline
\end{tabular}

\begin{tabular}{|c|c|c|c|c|c|c|c|}
\hline You & 1 & 2 & 3 & 4 & 5 & 6 & 7 \\
\hline Your partner & 1 & 2 & 3 & 4 & 5 & 6 & 7 \\
\hline \multicolumn{8}{|c|}{ 2. Help your child clean up his/her room or playroom } \\
\hline You & 1 & 2 & 3 & 4 & 5 & 6 & 7 \\
\hline Your partner & 1 & 2 & 3 & 4 & 5 & 6 & 7 \\
\hline \multicolumn{8}{|c|}{ 3. Stay home when your child is ill } \\
\hline You & 1 & 2 & 3 & 4 & 5 & 6 & 7 \\
\hline Your partner & 1 & 2 & 3 & 4 & 5 & 6 & 7 \\
\hline \multicolumn{8}{|c|}{ 4. Activities outside the home, like taking your child to a park or a museum } \\
\hline You & 1 & 2 & 3 & 4 & 5 & 6 & 7 \\
\hline Your partner & 1 & 2 & 3 & 4 & 5 & 6 & 7 \\
\hline \multicolumn{8}{|c|}{ 5. Include your child in your activities such as shopping or cooking } \\
\hline You & 1 & 2 & 3 & 4 & 5 & 6 & 7 \\
\hline Your partner & 1 & 2 & 3 & 4 & 5 & 6 & 7 \\
\hline \multicolumn{8}{|c|}{ 6. Teach your child new skills } \\
\hline You & 1 & 2 & 3 & 4 & 5 & 6 & 7 \\
\hline Your partner & 1 & 2 & 3 & 4 & 5 & 6 & 7 \\
\hline
\end{tabular}


$\begin{array}{llllllll}\text { You } & 1 & 2 & 3 & 4 & 5 & 6 & 7 \\ \text { Your partner } & 1 & 2 & 3 & 4 & 5 & 6 & 7\end{array}$

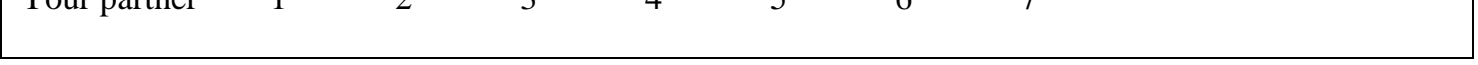




\section{BIBLIOGRAPHY}

Aldous, J., Mulligan, G. M., \& Bjarnason, T. (1998). Fathering over time: What makes the difference? Journal of Marriage and Family, 60, 809-820. doi:10.2307/353626

Barak, A., Feldman, S., \& Noy, A. (1991). Traditionality of children's interests as related to their parents' gender stereotypes and traditionality of occupations. Sex Roles, 24, 511-524. doi:10.1007/BF00289336

Barnett R.C., \& Baruch, G.K. (1987). Determinants of fathers' participation in family work. Journal of Marriage and the Family, 49, 29-40. doi:10.2307/352667

Berk, L. E. (2009). Child Development. Child development, eighth edition. Boston: Pearson Education, Inc.

Bouchard, G., \& Lee, C. M. (2000). The marital context for father involvement with their preschool children: The role of partner support. Journal of Prevention \& Intervention in the Community, 20, 37-53. doi:10.1300/J005v20n01_04

Brogan, D., \& Kutner, N. G. (1976). Measuring sex-role orientation: A normative approach. Journal of Marriage and the Family, 31-40.

Bronstein, P. (2006). The family environment: Where gender role socialization begins. In J. Worrell \& C. D. Goodheart (Eds.), Handbook of girls’ and women’s psychological health: Gender and well-being across the lifespan (pp. 262-271). New York: Oxford University Press.

Bulanda, R. E. (2004). Paternal involvement with children: The influence of gender ideologies. Journal of Marriage and Family, 66, 40-45. doi:10.1111/j.00222455.2004.00003.x 
Bussey, K., \& Bandura, A. (1999). Social cognitive theory of gender development and differentiation. Psychological Review, 106, 676-713. doi:10.1037/0033295X.106.4.676

Carlson, D. L., \& Knoester, C. (2011). Family structure and the intergenerational transmission of gender ideology. Journal of Family Issues, 32, 709-734. doi:10.1177/0192513X10396662

Chan, R. W., Brooks, R. C., Raboy, B., \& Patterson, C. J. (1998). Division of labor among lesbian and heterosexual parents: Associations with children's adjustment. Journal of Family Psychology, 12, 402-419. doi:10.1037/0893-3200.12.3.402

Cowan, C. P., \& Cowan, P. A. (1987). Men's involvement in parenthood: Identifying the antecedents and understanding the barriers. In P. W. Berman \& F. A. Pedersen (Eds.), Men's transitions to parenthood, 145-174.

Cunningham, M. (2001a). Parental influences on the gendered division of housework. American Sociological Review, 66, 184-203. doi:10.2307/2657414

Cunningham, M. (2001b). The influence of parental attitudes and behaviors on children's attitudes toward gender and household labor in early adulthood. Journal Of Marriage And Family, 63(1), 111-122. doi:10.1111/j.1741-3737.2001.00111.x

Deutsch, F. M., Lussier, J. B., \& Servis, L. J. (1993). Husbands at home: Predictors of paternal participation in childcare and housework. Journal Of Personality And Social Psychology, 65, 1154-1166. doi:10.1037/0022-3514.65.6.1154

Deutsch, F. M., \& Saxon, S. E. (1998). Traditional ideologies, nontraditional lives. Sex Roles, 38, 331-362. doi:10.1023/A:1018749620033 
Durkin, K., \& Nugent, B. (1998). Kindergarten children's gender-role expectations for television actors. Sex Roles, 38, 387-402. doi:10.1023/A:1018705805012

Edelbrock, C., \& Sugawara, A. I. (1978). Acquisition of sex-typed preferences in preschool-aged children. Developmental Psychology, 14, 614-623. doi:10.1037/0012-1649.14.6.614

Epstein, M., \& Ward, L. M. (2011). Exploring parent-adolescent communication about gender: Results from adolescent and emerging adult samples. Sex Roles, 65, 108118. doi:10.1007/s11199-011-9975-7

Erickson, R. J. (2005). Why emotion work matters: Sex, gender, and the division of household labor. Journal of Marriage and Family, 67, 337-351. doi:10.1111/j.0022-2445.2005.00120.x

Etaugh, C., \& Liss, M. B. (1992). Home, school, and playroom: Training grounds for adult gender roles. Sex Roles, 21, 129-147. doi:10.1007/BF00289754

Fagot, B. I., \& Hagan, R. (1991). Observations of parent reactions to sex-stereotyped behaviors: Age and sex effects. Child Development, 62, 617-628. doi:10.2307/1131135

Fan, P. L., \& Marini, M. M. (2000). Influences on gender-role attitudes during the transition to adulthood. Social Science Research, 29, 258-283. doi:10.1006/ssre.1999.0669

Fausto-Sterling, A., Coll, C. G., \& Lamarre, M. (2012). Sexing the baby: Part 2 applying dynamic systems theory to the emergences of sex-related differences in infants and toddlers. Social Science \& Medicine, 74, 1693-1702. doi:10.1016/j.socscimed.2011.06.027 
Fulcher, M. (2010). Individual differences in children's occupational aspirations as a function of parental traditionality. Sex Roles, 64, 117-131. doi:10.1007/s11199010-9854-7

Fulcher, M., Sutfin, E., \& Patterson, C. J. (2007). Individual differences in gender development: Associations with parental sexual orientation, attitudes, and division of labor. Sex Roles, 58, 330-341. doi:10.1007/s11199-007-9348-4

Gelman, S. A., Taylor, M. G., \& Nguyen, S. P. (2004). Mother-child conversations about gender [Monograph]. Monographs of the Society for Research in Child Development, 69, 1, 1-145. doi:10.1111/j.1540-5834.2004.06901004.x

Gervai, J., Turner, P. J., \& Hinde, R. A. (1995). Gender-related behavior, attitudes, and personality in parents of young children in England and Hungary. International Journal of Behavioral Development, 18, 105-126.

Giles, J. W., \& Heyman, G. D. (2005). Young children's beliefs about the relationship between gender and aggressive behavior. Child Development, 76, 107-121. doi:10.1111/j.1467-8624.2005.00833.x

Glauber, R., \& Gozjolko, K. L. (2011). Do traditional fathers always work more? Gender ideology, race, and parenthood. Journal of Marriage and Family, 73, 1133-1148. doi:10.1111/j.1741-3737.2011.00870.x

Goldberg, A. E., \& Perry-Jenkins, M. (2004). Division of labor and working-class women's well-being across the transition to parenthood. Journal of Family Psychology, 18, 225-236. doi:10.1037/0893-3200.18.1.225 
Goldberg, A. E., Kashy, D. A., \& Smith, J. Z. (2012). Gender-typed play behavior in early childhood: Adopted children with lesbian, gay, and heterosexual parents. Sex Roles, 67(9-10), 503-515. doi:10.1007/s11199-012-0198-3

Hood, J. C. (1986). The provider role: Its meaning and measurement. Journal of Marriage and Family, 48, 349-359. doi:10.2307/352402

Huston, A. C. (1983). Sex-typing. In Handbook of Child Psychology (4th edition), vol. 4. Mussen, P. H., (Ed.), Wiley: New York; 387-467.

Kroska, A. (2000). Conceptualizing and measuring gender ideology as an identity. Gender and Society, 14, 368-394. doi:10.1177/089124300014003002

Kulik, L. (2002). Like-sex versus opposite-sex effects in transmission of gender role ideology from parents to adolescents in Israel. Journal of Youth and Adolescence, 31, 451-457. doi:10.1023/A:1020263120774

Leve, L. D., \& Fagot, B. I. (1997). Gender-role socialization and discipline processes in one- and two-parent families. Sex Roles, 36, 1-21. doi:10.1007/BF02766236

Liben, L. S., Bigler, R.S., \& Krogh, H. R. (2002). Language at work: Children's gendered interpretations of occupational titles. Child Development, 73, 810-823. doi:10.1111/1467-8624.00440

Martin, C. L., \& Ruble, D. N. (2009). Patterns of gender development. Annual Review of Psychology, 61, 353-381. doi: 10.1146/annurev.psych.093008.100511

McHale, S. M., Crouter, A. C., \& Whiteman, S. D. (2003). The family contexts of gender development in childhood and adolescence. Social Development, 12, 125-148. doi:10.1111/1467-9507.00225 
Meteyer, K., \& Perry-Jenkins, M. (2010). Father involvement among working-class, dual-earner couples. Fathering, 8, 379-403. doi:10.3149/fth.0803.379

Moon, M., \& Hoffman, C. D. (2008). Mothers' and fathers' differential expectancies and behaviors: parent X child gender effects. The Journal of Genetic Psychology, 164, 261-279. doi:10.3200/GNTP.169.3.261-280

Nelson, M. C. (1988). Reliability, validity, and cross-cultural comparisons for the simplified attitudes toward women scale. Sex Roles, 18, 289-296. doi:10.1007/BF00288291

Pagano, M. E., Hirsch, B. J., Deutsch, N. L, \& McAdams, D. P. (2002). The transmission of values to school-age and young adult offspring: Race and gender differences in parenting. Journal of Feminist Family Therapy, 14, 13-36.

doi:10.1300/J086v14n03_02

Patterson, C. J., Sutfin, E. L., \& Fulcher, M. (2004). Division of labor among lesbian and heterosexual parenting couples: Correlates of specialized versus shared patterns. Journal of Adult Development, 11, 179-189.

doi:10.1023/B:JADE.0000035626.90331.47

Perkins, W. H., \& DeMeis, D. K. (1996). Gender and family effects on the "second-shift" domestic activity of college-educated young adults. Gender and Society, 10, 7893. doi:10.1177/089124396010001006

Perry-Jenkins, M., \& Crouter, A. C. (1990). Men's provider-role attitudes: Implications for household work and marital satisfaction. Journal of Family Issues, 11, 136156. doi:10.1177/019251390011002002 
Perry-Jenkins, M., Goldberg, A. E., Pierce, C. P., \& Sayer, A. G. (2007). Shift work, role overload and the transition to parenthood. Journal of Marriage and Family, 69, 123-138. doi:10.1111/j.1741-3737.2006.00349.x

Ruble, D. N., \& Martin, C. (1998). Gender development. In N. Eisenberg, \& W. Damon (Eds.), Handbook of child psychology, 5th ed: Vol. 3. Social, emotional, and personality and psychology, (pp. 933-1016). Hoboken, NJ, US: John Wiley \& Sons Inc.

Ruble, D. N., Martin, C., \& Berenbaum, S. A. (2006). Gender development. In N. Eisenberg, W. Damon, R. M. Lerner (Eds.), Handbook of child psychology: Vol. 3, Social, emotional, and personality development (6th ed.) (pp. 858-932). Hoboken, NJ, US: John Wiley \& Sons Inc.

South, S. J., \& Spitze, G. (1994). Housework in marital and nonmarital households. American Sociological Review, 59, 327-347. doi: 10.2307/2095937

Spence, J. T., \& Helmreich, R. (1972). The attitudes toward women scale: An objective instrument to measure attitudes towards the rights and roles of women in contemporary society. JSAS Catalog of Selected Documents in Psychology, 2 (66), 1-25.

Spence, J. T., Helmreich, R., \& Stapp, J. (1973). A short version of the attitudes toward women scale (AWS). Bulletin of the Psychonomic Society, 2, 219-220.

Sutfin, E. L., Fulcher, M., Bowles, R. P., \& Patterson, C. J. (2008). How lesbian and heterosexual parents convey attitudes about gender to their children: The role of gendered environments. Sex Roles, 58, 501-513. doi:10.1007/s11199-007-9368-0 
Trautner, H. M., Ruble, D. N., Cyphers, L., Kirsten, B., Behrendt, R., \& Hartmann, P. (2005). Rigidity and flexibility of gender stereotypes in childhood:

Developmental or differential? Infant and Child Development, 14, 365-381. doi:10.1002/icd.399

Turner, P. J., \& Gervai, J. (1995). A multidimensional study of gender typing in preschool children and their parents: Personality, attitudes, preferences, behavior, and cultural differences. Developmental Psychology, 31, 759-772. doi:10.1037/0012-1649.31.5.759

United States Department of Labor (2011). Women in the labor force: A databook. Washington, DC: United States Department of Labor.

Wickstrom, A. (2010). Influencing gender relations through child parent relationship therapy. International Journal of Play Therapy, 19 (2), 79-94. doi:10.1037/a00 